Review

\title{
Oncogene or Tumor Suppressor: The Coordinative Role of Lysine Methyltransferase SET7/9 in Cancer Development and the Related Mechanisms
}

\author{
Ye Gu $u^{1,2,3,4}$, Xiaofeng Zhang ${ }^{1,2,3}$, Weiping $\mathrm{Yu}^{4}{ }^{\bowtie}$, Weifeng Dong ${ }^{5^{\bowtie}}$ \\ 1. Department of Gastroenterology, Key Laboratory of Clinical Cancer Pharmacology and Toxicology Research of Zhejiang Province, Affiliated Hangzhou First People's \\ Hospital, Zhejiang University School of Medicine, Hangzhou, Zhejiang, P.R. China, 310006. \\ 2. Hangzhou Hospital \& Institute of Digestive Diseases, Hangzhou, Zhejiang, P.R. China, 310006. \\ 3. Key Laboratory of Integrated Traditional Chinese and Western Medicine for Biliary and Pancreatic Diseases of Zhejiang Province, Hangzhou, Zhejiang, P.R. China, \\ 310006. \\ 4. Department of Pathophysiology, Medical school of Southeast University, Nanjing, Jiangsu, P.R. China, 210009. \\ 5. Department of Laboratory Medicine, Cross Cancer Institute, University of Alberta, Edmonton, Alberta, Canada.
}

$\triangle$ Corresponding authors: Dr. Xiaofeng Zhang, Department of Gastroenterology, Key Laboratory of Clinical Cancer Pharmacology and Toxicology Research of Zhejiang Province, Affiliated Hangzhou First People's Hospital, Zhejiang University School of Medicine, Hangzhou, Zhejiang 310006, P.R.China. Tel: +86-0571-56006782; E-mail: zxf837@tom.com. Dr. Weiping Yu, Department of Pathophysiology, Medical school of Southeast University, 87 Ding Jia Qiao Road, Nanjing 210009, Jiangsu, China. Tel: +86-25-83272508; Fax: +86-25-84454318; E-mail: wpylg@hotmail.com. Dr. Wei-Feng Dong, Department of Laboratory Medicine, Cross Cancer Institute, University of Alberta, 11560 University Avenue, Edmonton, AB T6G 1Z2, Canada. Tel: +1 780 432-8780; Fax: +1 780 432-8780; E-mail: wei-feng.dong@cls.ab.ca.

(c) The author(s). This is an open access article distributed under the terms of the Creative Commons Attribution License (https://creativecommons.org/licenses/by/4.0/). See http://ivyspring.com/terms for full terms and conditions.

Received: 2020.12.29; Accepted: 2021.11.10; Published: 2022.01.01

\begin{abstract}
SET7/9 is a member of the protein lysine methyltransferase family that methylates both histone 3 lysine 4 (H3-K4) and lysine(s) of other non-histone proteins. In recent years, dis-regulation of SET7/9 were frequently detected in various cancer types and SET7/9-mediated methylation has been recognized as an important mechanism that affects cancer initiation and development through regulation of a series of cellular processes. Here we review the currently identified histone and non-histone protein targets of SET7/9 that are closely correlated with human cancer and the function of SET7/9 in regulating the expression and stability of its protein targets. The review also discusses the putative role of SET7/9 as an oncogene or tumor suppressor in the development of various cancer types and the underlying mechanisms, which may help better evaluate the potential of SET7/9 as a novel candidate for cancer therapy.
\end{abstract}

Key words: SET7/9; lysine methyltransferase; methylation; cancer developments

\section{Introduction}

Posttranslational modifications (PTMs) of histone proteins have a pivotal role in the dynamic transitions of chromatin structure in eukaryotes. Lysine methylation occurs on various histone lysine residues either site- or state-specifically, such as histone H3K4, H3K9, H3K79, and H4K20 [1]. It is a cardinal process underlying epigenetic modification of various tumor-related genes, leading to alterations in gene expression. So far many protein methylatransferases (PKMTs) that transfer different numbers of methyl groups from S-adenosyl-Lmethionine (AdoMet) to the $\varepsilon$-amino group of the target lysine have been identified [2-5]. Almost all of these protein methylatransferases harbor a conserved
SET domain, which is initially identified in Drosophila [6-8]. Recently, studies have revealed that PKMTs with conserved SET domain are not only responsible for histone lysine methylation, but also methylate various non-histone transcription factors important for a number of biological processes varying from cell growth, apoptosis, and stress response to DNA repair [9-13].

SET7/9 ((Su(var)-3-9, Enhancer-of-Zeste, Trithorax) domain containing protein 7/9), also referred to as SET7, SET9, SETD7, or KMT7, is one of the best characterized members of the SET domain PKMTs family. SET7/9 gene is located in human chromosome $4 \mathrm{q} 28$ with a protein product of 
approximately $50 \mathrm{kDa}$ [14]. Structural analyses have revealed that the SET7/9 protein is consists of an $\mathrm{N}$-terminal segment and a C-terminal segment (Fig. 1 ). The N-terminal segment is non-conserved, while the C-terminal segment contains the highly conserved SET domain flanked by the pre-SET and post-SET region and inserted with an i-SET region $[3,15,16]$. The cofactor and substrate bind in distinct clefts on the opposite surfaces of the SET domain [15-17] (Fig. 1). The N-terminal segment and pre-SET region in the C-terminal segment keep the structural stability of the protein $[3,16]$. On the other hand, the residues in the i-SET and post-SET domains are involved in interactions with the substrate together with the core SET domain $[16,17]$.

SET7/9 was originally identified as a histone H3K4-specific methyltransferase [14]. However, in the past decades many studies have found that SET7/9 preferentially targets non-histone proteins [18-23]. Although generally considered as an enzyme catalyzing monomethylation, SET7/9 can also catalyze dimethylation of some substrates, such as the Msx2-interacting nuclear target protein (MINT) and ribosomal protein (Rpl29) [24,25]. A consensus sequence motif of $\mathrm{K} / \mathrm{R}-\mathrm{S} / \mathrm{T} / \mathrm{A}-\mathrm{K}$ with $\mathrm{K}$ being the target lysine residue was initially found to be required for successful recognition by SET7/9 [26]. However, a more recent peptide-array analysis has expanded the recognition motif to: $(\mathrm{G} / \mathrm{R} / \mathrm{H} / \mathrm{K} / \mathrm{P} / \mathrm{S} / \mathrm{T})-(\mathrm{K}>\mathrm{R})-$ $(\mathrm{S}>\mathrm{K} / \mathrm{Y} / \mathrm{A} / \mathrm{R} / \mathrm{T} / \mathrm{P} / \mathrm{N})-\mathrm{K}-(\mathrm{Q} / \mathrm{N}>>$ other aa but not FYWPL)-(A/Q/G/M/S/P/T/Y/V), which implies a greater number of putative SET7/9 substrates to be discovered [24] (Fig. 2).

SET7/9-catalyzed histone H3K4 methylation and non-histone protein methylation often result in altered gene and protein expression [27,28]. In an endothelial model of SET7/9 knockdown, more than 8,000 genes were transcriptionally dis-regulated and hundreds of loci in regulatory elements lost H3K4me1, as revealed by RNA-seq and ChIP-seq [28]. The protein substrates of SET7/9 are often involved in the regulation of cellular processes including cell cycle, cell proliferation and differentiation, chromatin modulation, and DNA damage response. Meanwhile, many of these substrates also interact with each other, forming a complicated regulatory network (Fig. 3). Therefore, SET7/9-mediated methylation is an important mechanism that controls a series of physiological and pathological processes. Here we reviewed all the methylation targets of SET7/9 that are closely correlated with human cancer, and discussed the role of SET7/9 in cancer development through involvement in the regulation of cancer-related genes at both the transcriptional and posttranscriptional levels.

\section{Non-histone protein targets of SET7/9 and the biological functions}

\section{p53}

p53 is a transcription factor frequently mutated in human cancer [29]. It acts as a tumor suppressor protein that induces cell apoptosis and cell cycle arrest upon DNA damage via activation of its downstream target genes $[29,30]$. Upon DNA damage, p53 exerts its function by activating its downstream transcriptional targets, including pro-apoptotic factors Bax, Puma, Noxa, and p21/WAF/CIP. Protein p21 then inhibits the activities of cyclin-dependent kinases cdk2 and cdk1 (cdc2) as well as their partners cyclin E and cyclin B and promotes cell cycle arrest [31].

In human osteosarcoma cells U2OS, p21/WAF/ CIP was modulated through the SET7/9-p53 axis in response to DNA damage [18]. SET7/9 catalyzes mono-methylation of p53 at K372. The methylation level is enhanced by DNA damage, which stimulates subsequent acetylation of p53 and contributes to the stabilization and retention of p53 in the nucleus $[9,18]$ (Figs. 4, 5). Ultimately, the p21/WAF/CIP gene is activated and cell cycle arrest is induced [18] (Fig. 4). SET7/9-silenced U2OS cells were unable to undergo G2/M arrest, and expression of both p53 and p21 were remarkably decreased [18]. Furthermore, in colorectal cancer (CRC) cells HCT116, CO115, and SW480, function of SET7/9 is indispensable for resveratrol-driven p53 activation and cell apoptosis. Ablation of SET7/9 abolished resveratrol-induced overexpression of p53 as well as its downstream apoptotic markers PARP, and cleaved caspase-3 [32].

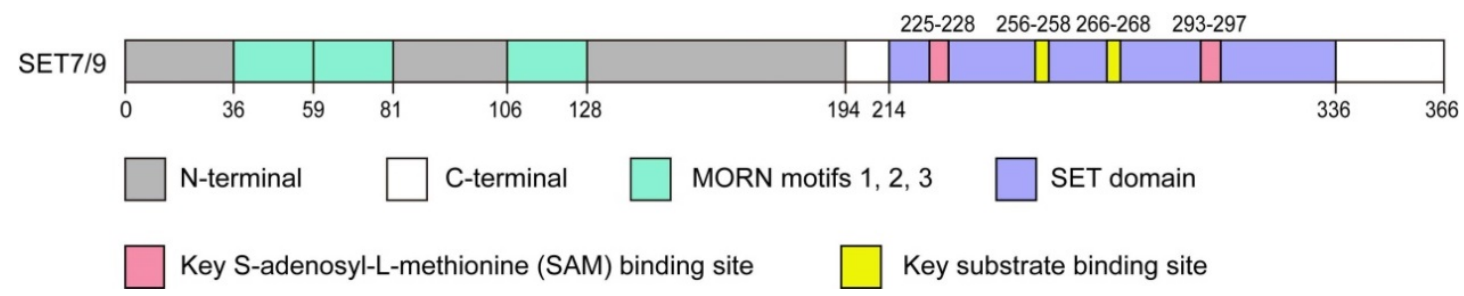

Figure 1. Schematic diagram of SET7/9. The SET7/9 protein contains an N-terminal segment and a C-terminal segment. The N-terminal helps stabilize SET7/9 protein and the C-terminal is mainly responsible for the catalytic function of SET7/9. The N-terminal contains three MORN motifs responsible for protein binding to plasma membrane phospholipids. The C-terminal contains the highly conserved SET domain. The cofactor SAM and protein substrate bind distinct sites on opposite surfaces of the SET domain. 
However, whether SET7/9 can directly regulate the expression of these pro-apoptotic factors or it only operates through p53 to activate them remained unknown.

$\begin{array}{ll}\text { P53 K372 } & \text { LKSKKKGQSTS } \\ \text { E2F1 K185 } & \text { KKSKKNHIQW } \\ \text { FXR K206 } & \text { CKSKRLRKNV } \\ \text { TAF10 K189 } & \text { SKSKDRKYTL } \\ \text { HIF-1a K32 } & \text { EKRKKSRVAA } \\ \text { UHRF1 K385 } & \text { KKAKMASATS } \\ \text { SUV39H1 K123 } & \text { QKAKQRRALR } \\ \text { FOXO3 K271 } & \text { AKKKAALQTA } \\ \text { ER K K02 } & \text { KRSKKNSLAL } \\ \text { GLI3 K436 } & \text { KRSKIKPDEDL } \\ \text { DNMT1 K142 } & \text { RRSKSDGEAK } \\ \text { SUV39H1 K105 HRSKTPRHLD } \\ \text { PCAF K89 } & \text { PRAKKLEKLG } \\ \text { GLI3 K595 } & \text { DRAKHQNRTH } \\ \text { NF-KB K37 } & \text { FRYKCEGRSA } \\ \text { YAP K494 } & \text { AATKLDKESFL } \\ \text { Histone 3 K4 } & \text { ARTKQTARKS }\end{array}$

Figure 2. Sequence alignment of a list of reported SET7/9 substrates and the recognition motifs. The asterisk indicates the targeted lysine residues methylated by SET7/9.
Although results from in-vitro studies have suggested an anti-tumor effect of SET7/9 through positive regulation of $\mathrm{p} 53$, the indispensible role of SET7/9 in the stabilization of p53 and regulation of p53-mediated DNA damage response is questioned by vivo experiments. Lehnertz et al. (2011) investigated the involvement of SET7/9 in p53 regulation using an independent knockout mouse strain with SET7/9 deficiency [33]. However, no defect in p53-dependent transcription following genotoxic and oncogenic insults was detected in cells from these mice. The canonical p53 functions were not impaired, either [33]. The results were confirmed by the study of Campaner et al. (2011), which further showed that SET7/9 was dispensable for p53 acetylation as well as p53-dependent cell-cycle arrest or apoptosis in mouse [34]. Unlike p53-deficiency, SET7/9-deficiency did not accelerate tumor onset and affect mouse survival and physiology in a murine model of Myc-induced lymphoma [33]. The most reasonable explanation for the disparity of in-vitro and in-vivo studies is that methylation of p53 by SET7/9 has no functional effect on p53 function. In support of

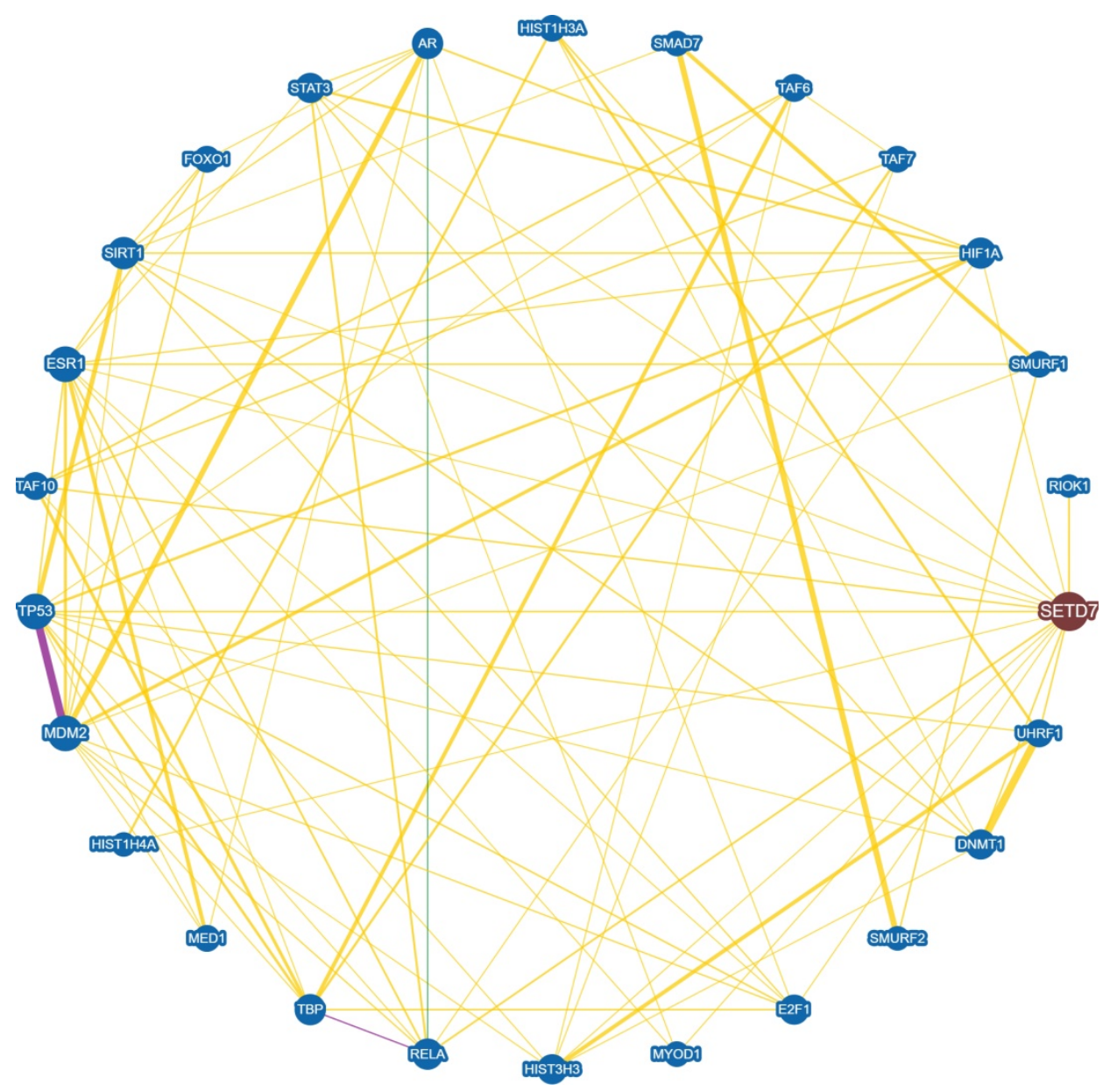

Figure 3. Interaction network between SET7/9 and SET7/9 substrates with experimental evidences. Protein interaction and genetic correlations are analyzed using the online tool BioGRID version 4.4 (https://thebiogrid.org/). Yellow line indicates direct physical interaction between two proteins. Green line indicates genetic interaction between two proteins. Purple line indicates both physical and genetic interaction between two proteins. 
this, no effect on the stabilization and activation of p53 was observed after substitution of the SET7/9 methylation site with arginine in mouse embryo fibroblasts (MEFs) [35]. Considering the complexity of cancer initiation and progression, which may result from dis-regulation of various oncogenes and tumor suppressor genes, abnormal SET7/9 expression might become a carcinogenic factor only when all other p53 regulatory pathways are disabled [33].

\section{E2F 1}

E2F1 belongs to the E2F transcription factor family. It is a key regulator of various cellular stressand apoptosis-related genes [36]. By activating its downstream target gene $p 73, \mathrm{E} 2 \mathrm{~F} 1$ can induce cell apoptosis independent of p53 [37]. Meanwhile, it also regulates the expression of CCNE, which encodes a protein named cyclin $\mathrm{E}$ that can directly interact with cdk2 to accelerate DNA replication and cell proliferation [38].

Unlike the stabilization effect brought about by SET7/9-mediated methylation on p53, SET7/ 9-mediated methylation of E2F1 K185 interferes with acetylation and phosphorylation of the protein, thus promotes its ubiquitylation and subsequent degradation [39,40] (Fig. 5). Hence, SET7/9 can negatively influence E2F1-mediated cell death independent of the p53-axis $[19,39,41]$. In p53-

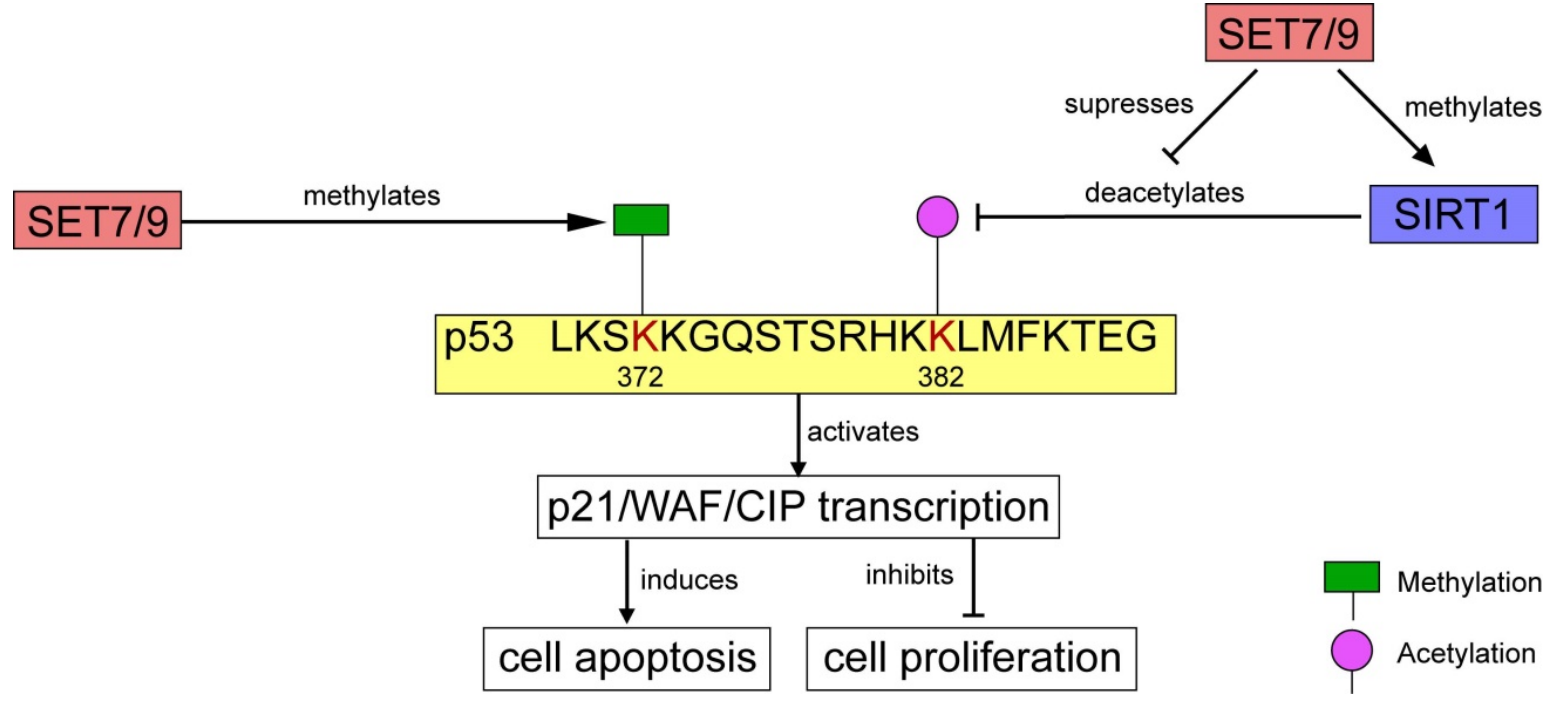

Figure 4. Regulation of p53 activity by SET7/9. On one hand, SET7/9-mediated methylation at p53 K372 stimulates subsequent acetylation and stabilization of p53. On the other hand, SET7/9 suppresses the interaction of SIRT1 and p53, thus abrogating SIRT1-mediated deacetylation of p53. The stabilized p53 protein further activates transcription of $p 2 I / W A F / C I P$, induces cell apoptosis and inhibits cell proliferation.

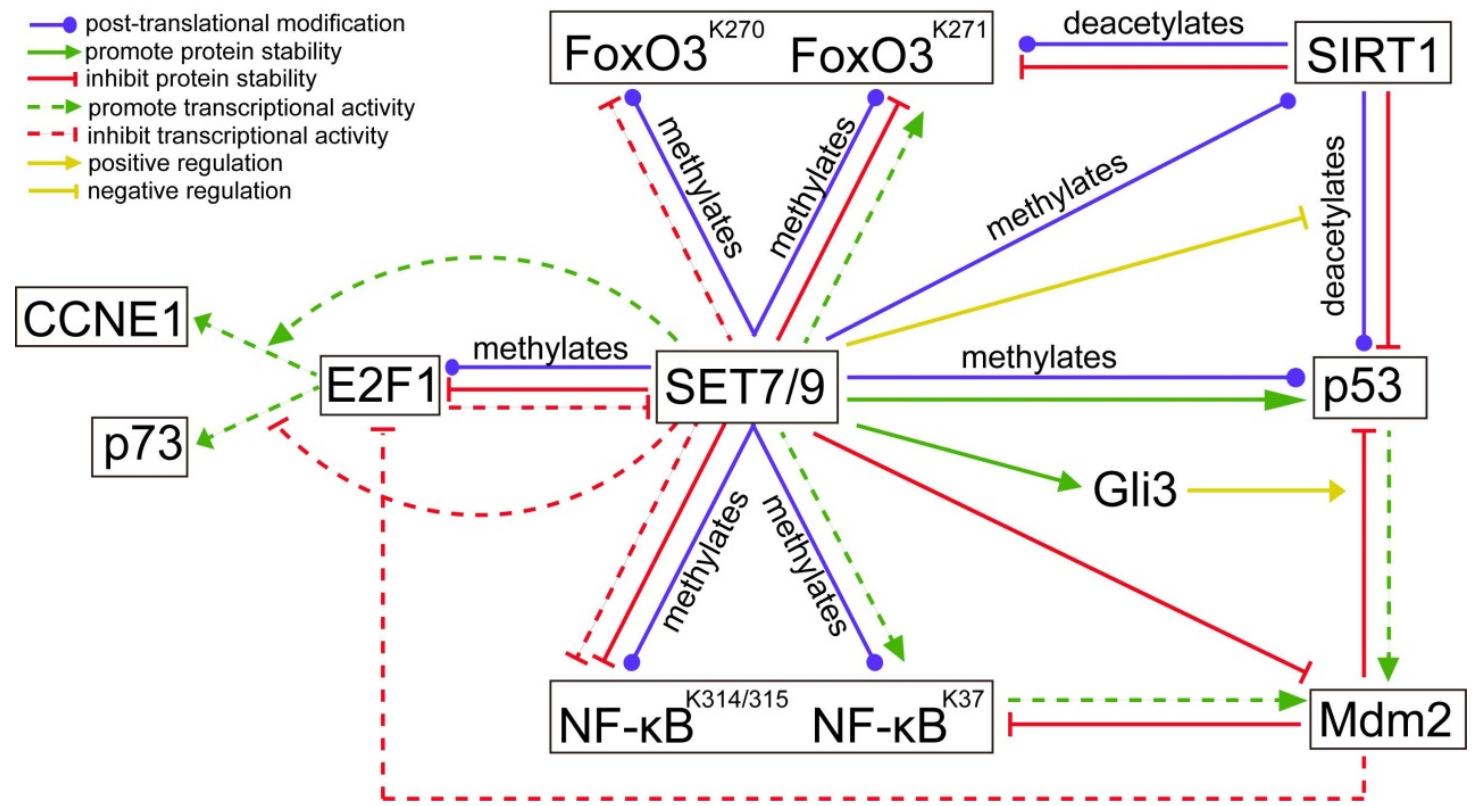

Figure 5. The regulatory network between known SET7/9 substrates that are important transcriptional factors involved in cancer development. The action type and effects depict the type of regulation between two proteins. 
deficient lung cancer cells H1299, overexpression of SET7/9 de-stabilized E2F1 protein and prevented activation of $p 73$, a downstream pro-apoptotic target of E2F1, thus inhibited cell apoptosis via a p53-independent pathway $[39,41]$. In turn, E2F1 may repress SET7/9 transcription in cooperation with Snail [40]. In breast cancer cells MCF7, silencing E2F1 resulted in significantly decreased Snail occupancy on both SET7/9 and E-cadherin promoters and evoked EMT transition [40] (Fig. 5).

In addition to direct methylation of E2F1, SET7/9 also modulates the binding of E2F1 on the promoter of its target genes. Chromatin immunoprecipitation (ChIP) assay revealed that SET7/9 co-activated CCNE1 transcription but repressed $p 73$ transcription downstream of E2F1 through chromatin modification [19] (Fig. 5). As a result, increased number of SET7/9-silenced cells in G1/S after genotoxic stress was observed in both H1299 and U2OS cell line irrespectively of the p53 status and source of DNA damage [19]. This suggests that SET7/9 is located upstream of E2F1 in the signal transduction cascade of DNA damage response, coordinating the final transcriptional outcome.

On the contrary, in hepatocellular carcinoma (HCC) cells Huh7 and colorectal cancer cells HCT116, SET7/9 stabilized E2F1 and up-regulated E2F1 downstream targets [42,43]. Decreased cell proliferation, migration and invasion were observed in SET7/9-silenced Huh7 cells as well as in wild-type Huh7 cells treated with MTA, suggesting that SET7/9 may be responsible for HCC development through post-translational regulation of E2F1 [43]. It was postulated that SET7/9-catalyzed methylation may lead to discrepant effects in the stability of its target protein depending on the types and amounts of post-translational modifiers under different cell contexts [43].

\section{Mdm2}

Except for the p53- and E2F1-dependent regulation of DNA damage response, SET7/9 can also affect DNA damage response and DNA repair via $\mathrm{Mdm} 2$, an E3 ubiquitin ligase that regulates the both p53 and E2F1 [44]. Previous studies have shown that Mdm2 blunts the transcriptional activity of E2F1 without triggering its degradation [45] (Fig. 5). Meanwhile, it inactivates p53 by targeting p53 for ubiquitin-mediated proteasomal degradation and interacting with and obscuring the N-terminal trans-activation domain of p53 [46]. In turn, p53 transcriptionally activates expression of Mdm2 [46] (Fig. 5). For cancers with wild-type or functional p53, targeting the interaction between MDM2 and p53 represents an attractive treatment approach [47].
Similarly, Mdm2 can bind to and inhibit the p65/RelA subunit of NF-KB, which also transcriptionally activates Mdm2 expression [48] (Fig. 5). The involvement of Mdm2 in the negative feedback loops with p53 and NF-KB has provided a novel mechanism of crosstalk between the p53 and NF-kB pathways.

Although direct methylation of $\mathrm{Mdm} 2$ by SET7/9 was not detected, evidences from GST pull-down assay proved that SET7/9 can physically interact with $\mathrm{Mdm} 2$, binding to its amino- and carboxyl-termini and decreased Mdm2 expression [44] (Fig. 5). In SET7/9-silenced U2OS cells, expression of p53 was down-regulated while expression of $\mathrm{Mdm} 2$ was up-regulated upon genotoxic stress [44]. Attenuation of SET7/9 led to increased DNA damage sensitivity and impaired DNA repair, while knockdown of both SET7/9 and Mdm2 negated the effect caused by knockdown of SET7/9 alone. The study implicated that SET7/9 operates in DNA damage response, at least partially via $\mathrm{Mdm} 2$ by acting as an antagonistic regulator. However, the exact consequences of interaction between SET7/9 and Mdm2 have remained unclear. As expression of $\mathrm{Mdm} 2$ also depends on transcriptional factors such as p53 or p73, it is unknown whether SET7/9 directly methylates Mdm2 and affects Mdm2 stabilization or indirectly suppresses Mdm2 expression via other regulators of Mdm2. Considering the physical binding of $\mathrm{Mdm} 2$ with several chromatin-associated factors, including E2F1, Tip60 and NBS1 [49], downstream effectors of the SET7/9-Mdm2 axis and related pathways should also been investigated to improve our understanding of SET7/9 in the molecular mechanisms of DNA damage in cancer cells.

\section{SIRT 1}

Apart from transcriptional factors, the methylation substrates of SET7/9 also include many histone modifiers, such as Sirtuin 1 (SIRT1), a mammalian nicotinamide adenine dinucleotide $\left(\mathrm{NAD}^{+}\right)$-dependentclass III histone deacetylase (HDAC) [50]. SIRT1 is generally considered as an oncogenic protein, which catalyzes deacetylation of several known tumor suppressors including p53 and FoxO [51,52]. Elevated SIRT1 expression is detected in various cancer tissues and cancer cell lines, such as leukemia and prostate cancer [53,54]. In HEK293T cells and HCT116 cells, SET7/9 directly interacts with SIRT1 and the interaction was markedly enhanced in response to DNA damage [50]. The interaction between SET7/9 and SIRT1 facilitated the dissociation of p53 from SIRT1, stabilized the acetylation level of p53, and increased p53-mediated transactivation [50] (Figs. 4, 5). In vitro methylation assay and mass 
spectrometry confirmed that SET7/9 catalyzes SIRT1 methylation at K233, K235, K236, and K238 [50,55]. Nevertheless, these methylation events do not affect the deacetylase activity of SIRT1. To explain the dissociation of p53 from SIRT1 mediated by SET7/9 and SIRT1 interaction, the authors proposed that SET7/9 may compete with p53 for binding to SIRT1, or methylation of SIRT1 by SET7/9 may induce conformational change in SIRT1 that prevents SIRT1 from binding to p53 [50]. Testing of these two hypotheses may provide a more complete understanding of how SIRT1 is regulated and how it in turn regulates its downstream targets, which will be valuable in the design of new anti-cancer therapies [50].

\section{NF-KB}

NF-kB is an important activator of cellular inflammatory responses with pathological implications. NF-KB mainly resides in the cytoplasm in an active form in normal un-stimulated cells. Upon multiple extracellular stimuli such as TNF-atreatment, activated NF-kB translocates into the nucleus and binds to the promoters of a diverse array of genes, through which NF-kB may promote the growth and survival of many solid and haematological maligancies [56]. NF-KB consists of homo- or heterodimers composed of many different subunits, with p65/RelA and p50 being the best characterized [57].

Using mass spectrometric analysis, the p65/ RelA subunit was found to be methylated at K314 or/and K315 by SET7/9 [13]. Methylation of p65/ RelA induces its ubiquitination and proteasomemediated degradation and represses the transcription activity of NF-KB [13] (Fig. 5). In U2OS and A549 cells, knockdown of SET7/9 or mutation at K314 or K315 prolonged DNA binding of NF- $\mathrm{KB}$ to its target genes in response to TNF- $\alpha$, indicating SET7/9-mediated negative regulation of NF-kB activation [13]. Consistently, a study using human U266 multiple myeloma cell line showed that berberine treatment increased SET7/9 expression, promoted p65/RelA methylation, and suppressed p65/RelA-dependent transactivation of miR-21. Berberine induced cell apoptosis and inhibited cell proliferation in a dosedependent manner, while knockdown of SET7/9 increased the nuclear level of p65/RelA and partially recovered cell proliferation [58].

Dramatically, SET7/9-mediated monomethylation of a different lysine site, K37 of NF-kB may lead to the completely opposite effects. In HeLa cells, methylation of NF-kB prompted interaction between p65/RelA and its target sequences, and selectively activating the expression of a subset of genes downstream of NF-kB [20] (Fig. 5). A possible explanation for the different regulatory effects of SET7/9 on NF-KB activity is that in HeLa cells p65/RelA K37 is exclusively methylated by SET7/9, while in U2OS cells p65/RelA K37 can be modified by other methyltransferases [20]. Similarly, silencing of SET7/9 in airway smooth muscle (ASM) cells decreased activation of NF-kB and inhibited TNF-ainduced cell proliferation and migration, but whether the regulatory effect is related with protein methylation was not reported [59].

\section{FoxO3}

The Forkhead Box $\mathrm{O}(\mathrm{FoxO})$ transcription factors are potent transcriptional activators regulating the expression of a wide range of target genes involved in stress response, cell metabolism, differentiation, and cell apoptosis. In mammal cells, FoxO transcriptional factors play a conserved role in tumor suppression. Activation of the FoxO member FoxO3 induces cell cycle arrest and promotes cell apoptosis in gastric cancer, pancreatic cancer, cervical cancer $[60,61]$, while loss of FoxO3 is associated with poor prognosis in estrogen-dependent breast cancer [62]. With the increased understanding of FoxO3, it is also found to be responsible for the sensitization of cancer cells to chemotherapy, which is of great clinical significance [63].

As the other members of the FoxO family, FoxO3 subjects to a post-translational modification at multiple lysine residues by a number of acetylases, methyltransferase, and ubiquitin enzymes. FoxO3 K270 and K271 were found to be two methylation targets of SET7/9 in 293T cells [64,65] (Fig. 5). SET7/9-mediated methylation of FoxO3 K270 inhibited binding of FoxO3 to its target genes and suppressed FoxO3 transactivation activity, thus reduced oxidative stress-induced expression of Bim downstream of FoxO3 [64]. On the contrary, SET7/9mediated methylation of FoxO3 K271, which is the site shown to be deacetylated by SIRT1, slightly increased FoxO3 transcriptional activity, but decreased FoxO3 stability [65] (Fig. 5). These results are not surprising given that SET7/9 can also inversely regulate the transcription of different downstream targets of E2F1 [19]. However, the biological effects of FoxO3 K270 and K271 methylation by SET7/9 need to be investigated in order to unravel the role of SET7/9-FoxO3 axis in cancer development. Meanwhile, whether the effects on FoxO3 activity and cellular biological feature caused by SET7/9 depend on the cell type or the type of target genes is also an interesting question to be addressed [65]. 


\section{Gli $1 / 3$}

The Gli zinc finger transcription factors are important modulators of oncogenic Hedgehog signaling [66]. Among the three Gli protein members, Gli1, Gli2, and Gli3, Gli3 has attracted great attention for its critical role in modulating the switch-on and -off of Shh signaling. Upon activation of Shh signaling, Gli3 transitions from a transcriptional repressor to a trans-activator that increases the expression of downstream targets including Gli1 and Ptch1 $[67,68]$. In pancreatic cancer, Gli3 mediates cell survival and increased cell resistance to cyclopamine, while in colorectal cancer, Gli3 augments tumorigenicity by up-regulating adherence-related genes $[69,70]$.

The study of $\mathrm{Fu}$ et al. (2016) reported that SET7/9 specifically methylates the full-length Gli3 at K436 and K595, increasing the stability and DNA-binding capacity of Gli3 on the promoter of Gli1 [71]. Gli3 acts as a critical transcriptional activator and amplifier of Shh signal. As a result, methylation of Gli3 by SET7/9 led to sustained activation of Shh signaling, followed by accelerated tumor growth and metastasis of non-small cell lung cancer (NSCLC) [71]. Moreover, the expression levels of SET7/9 and Gli1 showed a positive relationship in NSCLC tumor samples, indicating a regulatory role of the SET7/9-Gli3-Gli1 axis in NSCLC development [71]. Interestingly, in colorectal cancer cells, loss of Gli3 led to stabilization and activation of p53 via inhibition of Mdm2-mediated p53 ubiquitination and degradation [72] (Fig. 5). Since SET7/9 is proved to be the direct regulator of Gli3, p53, and Mdm2, discovery of the regulatory network composing of SET7/9, Gli3, p53, and Mdm2 has reinforced the significance of SET7/9 in regulating carcinogenesis through multiple molecules.

\section{ER $\alpha$ and $A R$}

Estrogen receptor a (ERa) and androgen receptor (AR) are nuclear hormone receptors essential for the regulation of cell differentiation, proliferation, and cell survival in breast cancer and prostate cancer. Once binding to estrogen or androgen, ERa and AR are translocated into the nucleus where they recruit co-activator complexes with histone acetyltransferase or methyltransferase activities to activate downstream target genes [12,73]. Methylation of ER at K302 by SET7/9 prevents ER ubiquitylation and degradation and stabilizes the protein [12]. Knockdown of SET7/9 resulted in a concomitant decrease in ERa expression and attenuated estrogen-driven transcriptional response. Meanwhile, binding of ER to its target genes such as PS2 and progesterone receptor $(P g R)$ was also inhibited after SET7/9 knockdown [12]. In vitro and in vivo analyses also revealed an inner relationship between two amino acid sites of ER, that is, K302 methylation of ERa is suppressed by mutation at K303R, which has been linked to more aggressive clinical features of breast cancer $[12,74,75]$. In order to determine the significance of K302 methylation in breast cancer development and evaluate the potential of SET7/9 as a biomarker or therapeutic target, the mutual impact between K302 methylation and other modifications of ERa needs to be investigated [12]. Similarly, methylation of AR K630 by SET7/9 potentiates the transcriptional activity of AR $[28,76]$. Although the effects of SET7/9-mediated ERa and AR methylation in cellular behavior were not examined, the importance of ERa and AR in stimulating cell proliferation and anti-apoptotic responses has implicated an indispensable role of SET7/9 in positive regulation of breast cancer and prostate cancer $[77,78]$.

\section{YAP}

The Yes-associated protein (YAP) functions as a transcriptional co-activator of genes controlling cell proliferation and apoptosis [79]. It is a transducer of the Hippo signaling, which regulates organ size and function $[80,81]$. Activation of Hippo signaling results from cell-cell contact, cell polarity, and other mechanical cues can ultimately lead to cytosolic retention and/or degradation of YAP (82). SET7/9 is required for the Hippo-mediated sequestration of YAP in the cytoplasm by methylation of K494 residue of the YAP protein [23] (Fig. 6). Lack of SET7/9 function in mice and murine embryonic fibroblasts (MEFs) resulted in accumulation of YAP in the nuclear and up-regulation of YAP-targeted genes $[23,83]$. What's more, a larger progenitor compartment in the intestine in SET7/9-deficient mice was observed [23]. Since dis-regulation of YAP is often associated with initiation of breast cancer, liver cancer, and colon cancer [84-86], the SET7/9dependent dynamic regulation of YAP localization may be another possible mechanism through which SET7/9 can affect cancer progression.

\section{$\beta$-catenin}

$\beta$-catenin is known to be an onco-protein and a key coordinator of the $\mathrm{Wnt} / \beta$-catenin signaling pathway $[87,88]$. Using mutagenesis assay and mass spectrometric analyses, a recent study has revealed that SET7/9 directly catalyzes mono-methylation of $\beta$-catenin K180 [89] (Fig. 6). After methylation, $\beta$-catenin was subject to ubiquitination and subsequent degradation mediated by phosphokinase glycogen synthase kinase (GSK)-3 $\beta$ [89] (Fig. 6). In $\mathrm{HeLa}$ cells with silenced SET7/9 expression, transcription of the typical $\beta$-catenin downstream 
gene targets, c-myc and cyclin D1, was significantly up-regulated, indicating the function of SET7/9 in inhibiting cell growth and proliferation via methylation of $\beta$-catenin K180 [89].

However, SET7/9 may cause the opposite consequences on the Wnt/ $\beta$-catenin pathway, as reported by another study [90]. In an established mouse intestine model, SET7/9 was responsible for higher susceptibility to tumorigenesis in the context of dis-regulated Wnt signaling. Wnt-dependent expression of the tumor stem cell marker Lgr5 and the proto-oncogene Myc were reduced after SET7/9 knockdown, supporting the finding that SET7/9 facilitates $W n t / \beta$-catenin-dependent tumorigenesis and regeneration [90]. The Yes-associated protein (YAP) is involved in this regulatory network by constituting a complex with SET7/9 and $\beta$-catenin (Fig. 6). SET7/9-dependent methylation of YAP prompts translocation of $\beta$-catenin to the nuclear $[23,90]$ (Fig. 6). The study has implicated the value of SET7/9 in clinical diagnosis and treatment for intestinal cancer [90]. In addition, the regulation of the Wnt/ $\beta$-catenin and Hippo/YAP pathways by SET7/9 revealed a methyltransferase-dependent mechanism that underlies the crosstalk between different signaling pathways during intestinal regeneration and tumorigenesis.

\section{HIF-1a}

Hypoxia-inducible factor-1a (HIF-1a), a heterodimeric complex comprising of an oxygenregulated a-subunit, is a hypoxia-inducible factor encoded by the HIFA gene. HIF-1a is a core transcription factor regulating cellular response to hypoxia signaling, which contributes to the aggressive through promoting cells to undergo the fundamental metabolism adaptation [91]. Dis-regulated HIF-1a is often associated with altered expression of genes controlling angiogenesis, cell survival, and tumor invasion [92]. In liquid chromatography mass spectrometry combined with co-immunoprecipitation analysis confirmed methylation of HIF-1a K32 by SET7/9, which leads to degradation of the protein by $26 \mathrm{~S}$ proteasomes [93]. In mouse embryonic fibroblasts (MEFs) under hypoxic stress, overexpression of SET7/9 led to reduced cell motility, while overexpression of lysine specific demethylase1 (LSD1) reversed the effect caused by SET7/9 and led to increased cell motility [93]. Moreover, mice with mutated HIF-1a displaying methylation defects showed accelerated retinal tumor vascularization and tumor angiogenesis $[93,52]$. The results implicated a different pathway through which SET7/9 functions to affect human cancer development.

\section{pRb}

The retinoblastoma tumor suppressor protein $(\mathrm{pRb})$ functions as a hub in the regulatory network orchestrating cell proliferation, differentiation, and survival [94]. Inactivation of $\mathrm{pRb}$ not only allows for inappropriate cell proliferation, but also undermines mitotic fidelity, genome instability and ploidy changes, which further promote tumor growth, tumor relapse and resistance to therapeutics [95]. Two lysine sites, K873 and K810 of pRb were found to be directly monomethylated by SET7/9 [96-98]. Methylation of

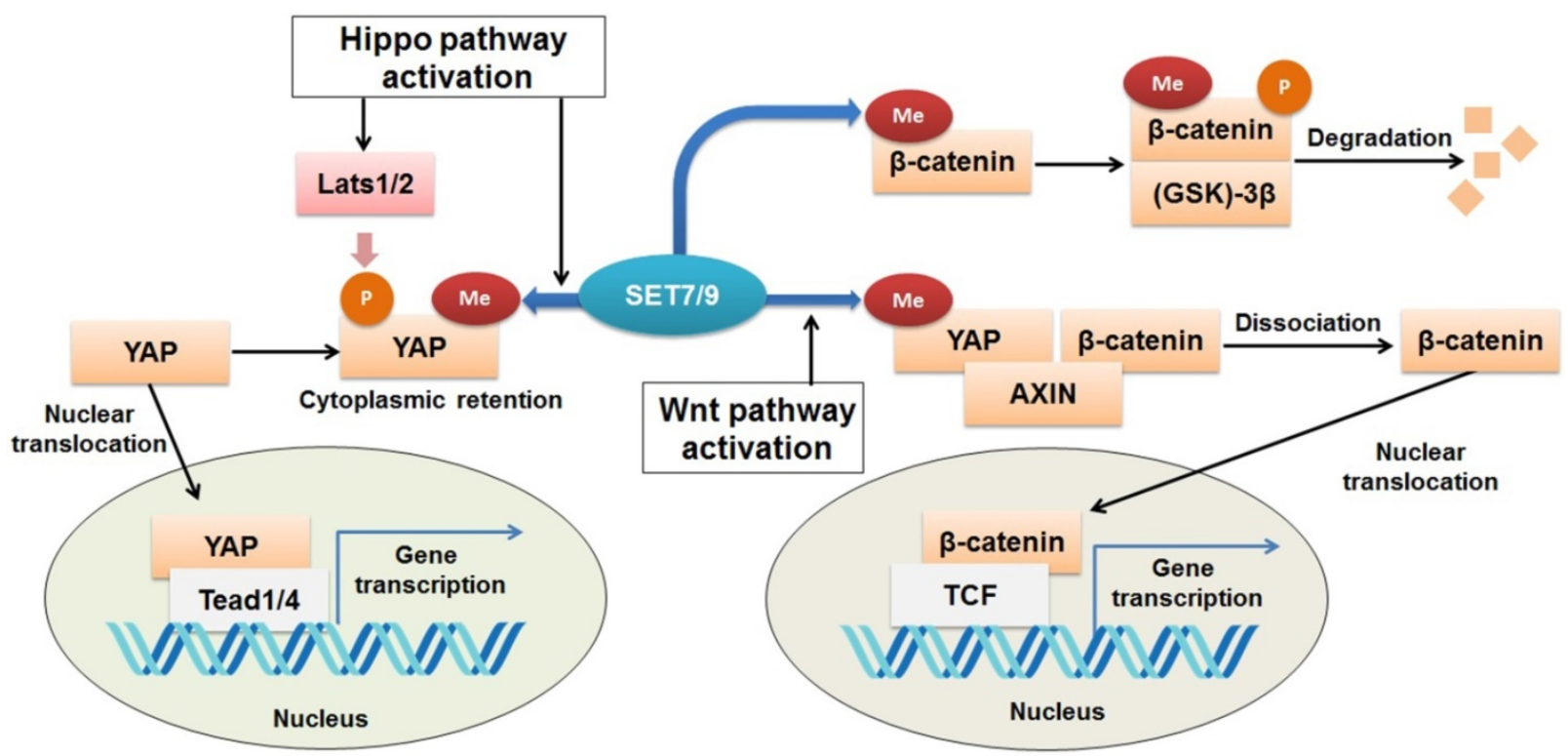

Figure 6. Regulation of Wnt/ 3 -catenin and Hippo signaling pathways by SET7/9. SET7/9 can methylate YAP K494 and $\beta$-catenin K180. Under normal conditions, methylation of $\beta$-catenin by SET7/9 promotes GSK-3ß-mediated ubiquitination and degradation of the protein. Upon Hippo signaling, methylation of YAP K494 by SET7/9 binds YAP in the cytoplasm, while upon Wnt signaling activation, methylation of YAP K494 by SET7/9 leads to dissociation of the YAP-AXIN- $\beta$-catenin complex, releases $\beta$-catenin and promotes its nuclear translocation, thus facilitates $\mathrm{Wnt} / \beta$-catenin-dependent tumorigenesis. 
pRb K873 is required for pRb-dependent cell cycle arrest and repression of the E2F family transcription factors [96] (Fig. 6). In osteosarcoma cell lines U2OS and SAOS2, knockdown of SET7/9 led to reduced cell cycle arrest and accumulation of protein products of many E2F target genes [96]. Methylation of pRb K810, the core subunit facilitating cdk phosphorylation, hinders interaction between $\mathrm{pRb}$ and $\mathrm{Cdk}$, thus inhibits $\mathrm{pRb}$ phosphorylation and augments cell growth inhibition [97] (Fig. 7). Methylated pRb K810 can also be recognized by p53 binding protein 1 (53BP1), forming a chromatin-bound $\mathrm{pRb} / 53 \mathrm{BP} 1$ complex on E2F target genes. The interaction between 53BP1 and methylated $\mathrm{pRb}$ enables $\mathrm{pRb}$ to participate in pathways regulating cell cycle progression and influencing the DNA-damage response [98].

\section{UHRF 1}

Ubiquitin-like containing PHD Ring Finger 1 (UHRF1) is a key epigenetic regulator required for maintenance of DNA methylation and heterochromatin formation. UHRF1 is primarily expressed in proliferating cells, promoting S-phase entry. Up-regulation of UHRF1 may serve as a biomarker for a variety of cancers; including breast, gastric, prostate, lung and colorectal carcinoma [99-104]. In HCT116 and H1299 cells, UHRF1 is methylated by SET7/9 at K385 in response to DNA damage [105]. SET7/9-mediated methylation of UHRF1 promotes its interaction with proliferating cell nuclear antigen (PCNA), which functions in DNA replication and cell cycle regulation [105]. Enhanced UHRF1-PCNA interaction further leads to polyubiquitination of PCNA and induction of homologous recombination and finally facilitates cell survival [105]. HCT116 cells overexpressing UHRF1 showed increased cell viability whereas methylationdeficient mutants showed reduced cell viability [105].
On the contrary, the histone H3K4 demethylase LSD1 can de-methylate UHRF1 and blocks polyubiquitination of PCNA [105]. The methylation status of UHRF1 dynamically controlled by SET7/9 and LSD1 in double-strand break repair pathway is essential for cell viability and survival, which may contribute to tumor progression and metastasis [105].

\section{SUV39HI}

Suppressor of variegation 3-9 homolog 1 (SUV39H1) is a histone methyltransferase that catalyzes H3K9 tri-methylation [106]. The function of SUV39H1 in cancer development is pleiotropic. Generally, SUV39H1 is regarded as a tumor suppressor for its role in inhibition of genes required for cell proliferation [107]. However, an oncogenic role of SUV39H1 has been reported in retioblastoma and clear cell renal cell carcinoma and up-regulation of SUV39H1 has been observed in several human cancers, such as colorectal cancer, bladder cancer, and hepatocellular carcinoma [108-112]. SUV39H1 can be methylated at K105 and K123 by SET7/9 [21]. This modification suppresses the methyltransferase activity of SUV39H1, inhibits H3K9 tri-methylation, and causes relaxation of the heterochromatin condensation [21]. MEFs cells with silenced SET7/9 expression were less sensitive to DNase digestion and more resistant to Adr-induced genome instability due to decreased SUV39H1 methylation [21]. Furthermore, H1299 cells expressing wild-type SUV39H1 proliferated slower than those expressing SUV39H1-2KR with mutated methylation loci, suggesting that genome instability induced by SUV39H1 methylation restrains cell proliferation and tumor growth [21]. The study confirmed the participation of SET7/9 in the modulation of genome stability and provides a new insight into the role of SET7/9 in cancer development [21].
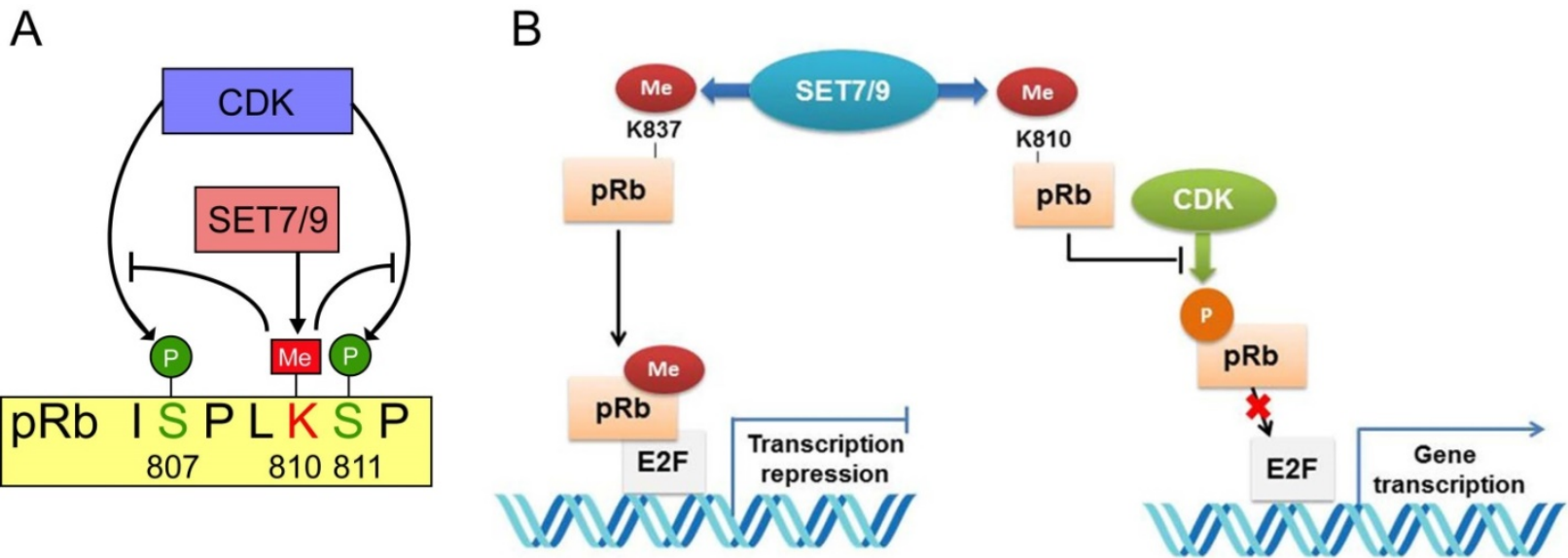

Figure 7. Interplay between pRb lysine methylation by SET7/9 and phosphorylation by CDK in the control of cell cycle and cell growth. (A) SET7/9 methylates pRb at K810 and hinders phosphorylation of pRb at S807 and S811 by CDK. (B) Methylation of pRb K837 is required for the repression of the E2F family transcription factors and $\mathrm{pRb}$-dependent cell cycle arrest. Methylation of $\mathrm{pRb}$ K810 impedes phosphorylation of $\mathrm{pRb}$ and prevents dissociation of $\mathrm{pRb}$ from E2F transcription factors. 


\section{DNMT1}

As one of the three active DNA cytosine methyltransferases, DNMT1 plays a principal role in maintaining the existing methylation marks of $\mathrm{CpG}$ sites during DNA replication [113]. Deregulation of DNMT1 expression or complete loss of DNMT1 in cancer cells led to hemi-methylation of one fifth of CpG islands in the genome, coupled with G2 cell cycle arrest [114]. DNMT1 and SET7/9 are reciprocally regulated, forming a negative feedback loop [40]. Both DNMT1 K142 and K1096 can be methylated by SET7/9, but K142 serves as the major target of SET7/9 [27,115]. SET7/9-mediated DNMT1 K142 methylation caused subsequent proteasome-mediated degradation of DNMT1 and reduced genomic DNA methylation $[27,115,116]$. Meanwhile, DNMT1 represses SET7/9 transcription by methylation of its gene promoter [40]. The expression levels of SET7/9 and DNMT1 proteins were inversely correlated in clinical samples of breast cancer [40]. What's more, silencing of SET7/9 in breast cancer cells MCF7 reduced cell-cell adhesion and induced EMT transition [40]. However, for human cervical cancer cells Hela, though silencing of SET7/9 affected normal cell cycle arrest upon DNA damage, no dramatic phenotypic changes were observed. The current findings imply that the interplay between SET7/9 and DNMT1 may act as a fine-tune mechanism related with epigenetic modulation of gene expression in different cancer types [115].

\section{HDAC6}

Belonging to the histone deacetylases (HDACs) family, HDAC6 is a key regulator of cytoskeleton, stress response, cell motility, and oncogenesis [117].

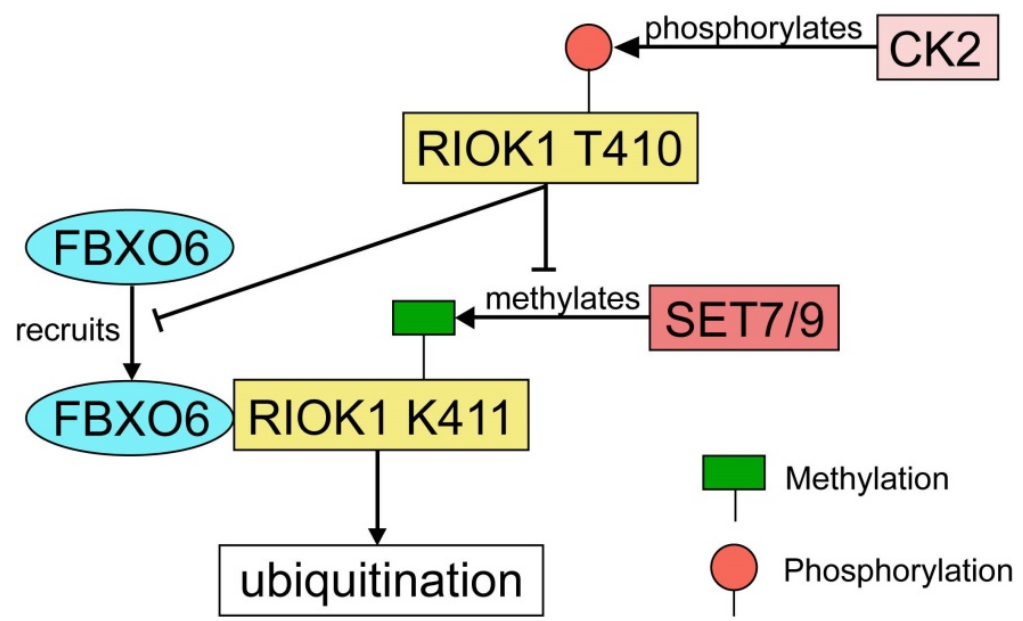

Figure 8. The regulatory network of RIOK1 by SET7/9, FBXO6, and CK2. SET7/9 methylates RIOK1 at K411. FBXO6 specifically interacts with K411-methylated RIOK1 through its FBA domain to induce RIOK1 ubiquitination. On the contrary, CK2 phosphorylates RIOK1 T410 and stabilizes the protein by antagonizing K411 methylation and impeding the interaction between FBXO6 and RIOK1.
Except for its role in maintenance of de-acetylation balance of histones, HDAC6 also de-acetylates non-histone substrates including a-tubulin and cortactin [118,119]. Direct-interaction was detected between SET7 and HDAC6 in CRC cells HCT116 and SW480 [120]. The interaction did not change the endogenous HDAC6 expression, but inhibited the de-acetylation activity of HDAC6 which further resulted in significantly reduced cell viability and migration on CRC cells [120]. SET7/9 overexpression in CRC cells caused HDAC6-dependent inhibition of cell proliferation and wound healing rate [120]. In addition, overexpression of SET7/9 reserved the activation effect of HDAC6 on MAPK/ERK signaling [120]. This study, together with the study of SET7/9 and $\mathrm{Mdm} 2$, has revealed a different way through which SET7/9 can affect protein expression or activity by protein-protein interaction without exerting its lysing methylation function $[44,120]$. However, the inner mechanisms underlying the regulatory effect of SET7/9 on these targets deserve to be further investigated.

\section{RIOK1}

RIOK1 is a member of the conserved Rio (right open reading frame) family of atypical serine/threonine kinases [121]. Although the function of PIOK1 in mammalian cancers has not been well-characterized, RIOK1 upregulation was found to be positively associated with Akt activity in both glioblastoma specimens and cultured cells [122]. Meanwhile, a study using isogenic colon-, breast- and lung cancer cell lines has demonstrated that knockdown of RIOK1 strongly impairs cell proliferation and invasiveness [123]. In both CRC and gastric cancer tissues, the expression of RIOK1 is significantly upregulated [124]. RIOK1 is specifically mono-methylated at the K411 site by SET7/9 and the methylation is reversed by LSD1 [124]. SET7/9mediated methylation recruits FBXO6 E3 ligase and contributes to RIOK1 ubiquitination, which finally resulted in reduced tumor growth and metastasis in mice model with CRC [124]. On the other hand, RIOK1 T410 is phosphorylated by casein kinase 2 (CK2), which stabilizes RIOK1 by antagonizing K411 methylation and impeding the interaction between FBXO6 and RIOK1 [124] (Fig. 8). In support of this, the expression levels of CK2 and LSD1 were inversely correlated with the expression levels of SET7/9 and FBXO6 in human CRC tissues [124]. 


\section{Other cancer-related methylation substrates of SET7/9}

Beside all the proteins discussed above, SET7/9-catalyzed methylation of some other non-histone proteins with a potential role in cancer development has also been uncovered. For example, TAF10, a subunit of the TFIID transcription factor also known as TAFII30, is efficiently methylated by SET7/9 at K189 in vitro and in vivo [125]. Methylation of TAF10 K189 increases its binding capacity to RNA polymerase II and probably stimulates the formation of pre-initiation complex [125]. The dynamic interaction between SET7/9 and gene regulatory regions of TAF10 downstream targets enables the activation of specific TAF10-dependent genes, such as ERF1 and ERA1 [125]. By contrast, methylation of STAT3 at K140 by SET7/9 is a negative regulatory event that blocks activation of many STAT3 target genes, including SOCS3, FGF21, and IRF8/9 [126].

Other newly identified substrates of SET7/9 include the p300/CBP-associated factor (PCAF) as well as the farnesoid $X$ receptor (FXR) $[127,128]$. As revealed by in-vitro mapping experiments, six lysine residues, K78, K89, K638, K671, K672, and K692 of PCAF as well as K206 of FXR can be methylated by SET7/9 [127,128]. Undoubtedly, the above methylation events are correlated with gene expression pattern and cellular process. However, whether SET7/9-mediated methylation of these protein targets are directly linked with cellular malignant phenotype and cancer initiation needs to be further investigated.

\section{SET7/9-mediated histone modification and the biological functions}

\section{SET7/9 catalyzes H3K4mel in the promoters of NF-KB and NF-KB target genes}

Despite the fact that SET7/9 functions primarily through the methylation of various non-histone proteins, involvement of SET7/9-mediated histone methylation in epigenetic regulation of gene expression should not been overlooked. SET7/ 9-catalyzed methylation of histone $\mathrm{H} 3 \mathrm{~K} 4$, which is known be a pervasive mark of enhancers, has been identified on the promoter regions of many cancerrelated genes such as $N F-\kappa B, F X R$, and the vascular endothelial growth factor (VEGF) [128-131].

A microarray study in TNFa-stimulated human monocytes found that SET7/9 is responsible for the co-activation of one fourth of NF-KB downstream target genes. H3K4 mono-methylation was observed on the promoter regions in several specific inflammatory genes such as $M C P-1, I L-8$, and TNF- $\alpha$ regulated by NF-kB [128]. Activation of these inflammatory genes is closely related with tumor metastasis and angiogenesis [132]. It is notable that not all NF-KB downstream targets are regulated by SET7/9. In HEK293 cells and HeLa cells, silencing of SET7/9 suppressed both IP-10 and TNF- $\alpha$ expression, but did not affect $I \kappa B \alpha$ expression, suggesting that the regulation of NF-kB signaling by SET7/9 might be promoter-specific $[13,20]$. More recently, H3K4 methylation specifically catalyzed by SET7/9 on NF-kB p65 promoter has also been verified. Epigenetic modification of NF-KB driven by SET7/9 contributes to vascular disorder in patients with type 2 diabetes mellitus [130]. To sum up, the current studies supported a role of SET7/9 in both transcriptional and translational regulation of the NF-kB pathway.

\section{SET7/9 catalyzes H3K4mel in the promoter of VEGF}

Vascular endothelial growth factor (VEGF) is an important regulator of tumor angiogenesis frequently up-regulated in cancer [133]. By forming a complex with GATA1 that binds to the GATC site in the promoter region of VEGF, SET7/9 is able to control GATA1-induced VEGF transcription [131]. Enrichment of H3K4 mono-methylation was observed at the GATC site in the promoter region of VEGF [131]. In breast cancer cells, knockdown of SET7/9 not only reduced VEGF promoter activity and decreased $V E G F$ expression at the mRNA level, but also abolished the ability of GATA1 to activate VEGF [131]. Furthermore, regulation of cellular behavior, tumor growth, and angiogenesis of breast cancer by GATA-1 is dependent of the function of SET7/9 [131]. In clinical breast cancer samples, both GATA1 and SET7/9 are overexpressed and their expression levels were significantly correlated with tumor size, grade, and VEGF expression [131].

\section{SET7/9 regulates $\mathrm{H} 3 \mathrm{~K} 4 \mathrm{me} 3$ in the promoter of LncRNA DRAIC}

Long noncoding RNAs (lncRNAs) are defined as transcripts larger than $200 \mathrm{nt}$ without protein-coding potential. Many lncRNAs bind to chromatinmodifying proteins and recruit their catalytic activity to specific sites in the genome, thereby guide epigenetic regulations in both physiological and pathological conditions [134]. Cumulative evidences point to a critical role of lncRNAs in cancer initiation and progression [135-139].

Similar to protein-coding transcripts, transcriptional of lncRNAs is subject to typical histone modification-mediated regulation. DRAIC, also known as LOC145837 and RP11-279F6.1 is the first lncRNA reported to be transcriptionally regulated by 
SET7/9 [140]. In human glioma samples, both SET7/9 and lncRNA DRAIC were down-regulated compared with adjacent non-cancerous normal tissues. SET7/9 enhanced H3K4me3 enrichment on the promoter of DRAIC and promoted DRAIC transcription [140]. Overexpression of SET7/9 and DRAIC inhibited proliferation, invasion, and migration of U251 cells. The study provided evidences for the involvement of SET7/9 in tri-methylation of H3K4 and suggested a novel mechanism controlling glioma growth and metastasis via the SET7/9-DRAIC axis [140].

\section{Involvement of SET7/9 in other forms of histone modification}

Apart from direct H3K4 methylation, SET7/9 may exert its function as a transcriptional regulator by participating in other forms of histone modification. As mentioned above, SET7/9 selectively activates or represses E2F1 downstream factors CCNE1 and $p 73$ [19]. Interestingly, although recruitment of SET7/9 to the promoters of these genes was confirmed by ChIP assay, altered SET7/9 expression did not change the level of H3K4 mono-methylation, but increase the level of H3K9 tri-methylation [19]. This finding demonstrated the diverse mechanisms through which SET7/9 can regulate gene expression at the transcriptional level.

Besides, the histone methylation targets of SET7/9 are not limited to H3, strong methylation of free $\mathrm{H} 2 \mathrm{~A}$ and $\mathrm{H} 2 \mathrm{~B}$ histone proteins, which is comparable with $\mathrm{H} 3$ methylation catalyzed by SET7/9 has also been detected by peptide array analysis [24]. As a part of histone $\mathrm{H} 3$ and $\mathrm{H} 4$ carry some modifications before incorporating into chromatin [141], SET7/9-catalyzed methylation of free $\mathrm{H} 2 \mathrm{~A}$ and $\mathrm{H} 2 \mathrm{~B}$ may change the dynamic and physiological state of chromatin and affect gene transcription [24]. This will be an interesting topic of future study.

\section{Other genes transcriptionally regulated by SET7/9 via histone modification}

Compared with the non-histone targets of SET7/9, gene targets transcriptionally regulated by SET7/9 is less well-understood. However, more and more gene promoters subject to SET7/9-mediated H3K4 methylation or other forms of histone modification are being uncovered. In gastric cancer cells knockdown of SET7/9 inhibited expression of SREK1IP1, PGC, and CCDC28B, accompanied by decreased H3K4me1 level at promoter regions of these genes [142]. Accordingly, cell proliferative, migratory, and invasive abilities were significantly increased, and activation of matrix metalloproteinase genes (MMP1, MMP7, and MMP9) was detected [142].

Moreover, chromatin immunoprecipitationbased deep sequencing (ChIP-seq) revealed more than 20,000 SET7/9 specific binding sites in breast cancer cell line MCF-7 [143]. ChIP assay confirmed the enrichment of SET7/9 to the promoter of RUNX2, a transcription factor involved in bone development [143]. Depletion of SET7/9 led to decreased RUNX2 expression and slower tumor growth [143]. However, whether the regulatory effect of SET7/9 on RUNX2 expression results from $\mathrm{H} 3 \mathrm{~K} 4$ methylation or other types of chromatin modulation merit further investigation.

\section{Role of SET7/9 in human cancer development}

Despite the discovery of various methylation substrates or interactors of SET7/9, most studies of SET7/9 have been limited at the cellular level and the specific role of SET7/9 in different types of human cancer has not been thoroughly examined.

For example, the human osteosarcoma tumor cell line U2OS and human cervical cancer cell line HeLa were frequently used for establishing SET7/9-overexpressing or SET7/9-silencing models to examine the interaction between SET7/9 and its substrates and the cellular biological effects of altered SET7/9 expression. In both cell lines, knockdown of SET7/9 may give rise to a series of malignant phenotype including accelerated cell growth and proliferation, increased cell motility, and reduced cell cycle arrest (Table 1), indicating a potential tumorsuppressor role of SET7/9 in these cells. However, for both human osteosarcoma tumor and cervical cancer, further study on the expression of SET7/9 in clinical tumor samples and the correlation between SET7/9 expression and clinical characteristics remain to be examined to fully confirm the results from in-vitro cellular studies.

In human gastric cancer and glioma, both clinical study and cellular analyses support a tumor suppressor role of SET7/9 [140,142]. SET7/9 enhanced transcription of the SREK1IP1, PGC, $C C D C 28 B$ genes and the LncRNA DRAIC through H3K4 methylation in the promoter regions and inhibited cell proliferation, migration, and invasion [140,142] (Table 1). Clinically, the expression of SET7/9 was down-regulated in tumor samples of gastric cancer and glioma [140,142]. Meanwhile, lower SET7/9 expression is significantly correlated with better survival of patients with gastric cancer [142] (Table 1). 
Table 1. Functions of SET7/9 and relevant substrates and co-regulators of SET7/9 in different cancer types

\begin{tabular}{|c|c|c|c|c|c|c|}
\hline Cancer type & $\begin{array}{l}\text { Role of } \\
\text { SET7/9 }\end{array}$ & $\begin{array}{l}\text { SET7/9 expression } \\
\text { in clinical sample }\end{array}$ & Clinical significance & $\begin{array}{l}\text { Substrates or } \\
\text { interactors }\end{array}$ & $\begin{array}{l}\text { Effects of methylation/ } \\
\text { interaction }\end{array}$ & Biological effects of SET7/9 knockdown \\
\hline \multirow[t]{4}{*}{$\begin{array}{l}\text { Human breast } \\
\text { cancer }\end{array}$} & \multirow[t]{4}{*}{ Controversial } & \multirow[t]{3}{*}{$\begin{array}{l}\text { Overexpression } \\
\text { [131] }\end{array}$} & \multirow{3}{*}{$\begin{array}{l}\text { SET7/9 up-regulation is } \\
\text { positively correlated with } \\
\text { tumor size and grade; } \\
\text { Higher SET7/9 } \\
\text { expression indicates } \\
\text { worse survival [131] }\end{array}$} & VEGF (H3K4) [131] & $\begin{array}{l}\text { Transcription } \\
\text { activation }\end{array}$ & $\begin{array}{l}\text { Decreased cell proliferation, migration, } \\
\text { tube formation, tumor growth, and } \\
\text { angiogenesis abilities [131] }\end{array}$ \\
\hline & & & & $\begin{array}{l}\text { Estrogen Receptor } \alpha \\
\text { (K302) [12] }\end{array}$ & Stabilization of ERa & $\begin{array}{l}\text { Attenuated estrogen-driven transcriptional } \\
\text { response; } \\
\text { Impaired recruitment of ERa to its target } \\
\text { genes } P S 2 \text { and } P g R[12]\end{array}$ \\
\hline & & & & RUNX2 (H3K4) [143] & $\begin{array}{l}\text { Transcription } \\
\text { activation }\end{array}$ & $\begin{array}{l}\text { Inhibited tumor growth; } \\
\text { Inhibited cell migration and invasion [143] }\end{array}$ \\
\hline & & $\begin{array}{l}\text { Down-regulation } \\
{[40]}\end{array}$ & $\begin{array}{l}\text { Low SET7/9 expression } \\
\text { indicates better overall } \\
\text { survival and disease-free } \\
\text { survival [40] }\end{array}$ & $\begin{array}{l}\text { E2F1 (K185) DNMT1 } \\
\text { [40] }\end{array}$ & $\begin{array}{l}\text { Degradation of E2F1 } \\
\text { and DNMT1 }\end{array}$ & $\begin{array}{l}\text { Induction of EMT, disruption of cell-cell } \\
\text { adhesion and generation of cells with stem } \\
\text { cell-like properties [40] }\end{array}$ \\
\hline \multirow{5}{*}{$\begin{array}{l}\text { Human } \\
\text { colorectal } \\
\text { cancer }\end{array}$} & \multirow[t]{5}{*}{ Controversial } & \multirow[t]{2}{*}{$\begin{array}{l}\text { Overexpression } \\
{[145]}\end{array}$} & \multirow{2}{*}{$\begin{array}{l}\text { SET7/9 up-regulation is } \\
\text { positively correlated with } \\
\text { tumor stage and } \\
\text { microsatellite instability } \\
\text { [145] }\end{array}$} & E2F1 (K185) [42,145] & Stabilization of E2F1 & $\begin{array}{l}\text { Decreased cell proliferation, migration and } \\
\text { invasion [42] }\end{array}$ \\
\hline & & & & - & - & $\begin{array}{l}\text { Decreased cell proliferation; } \\
\text { Increased G1/S cell cycle arrest; } \\
\text { Increased cell apoptosis [145] }\end{array}$ \\
\hline & & \multirow[t]{3}{*}{$\begin{array}{l}\text { Down-regulation } \\
{[120,124]}\end{array}$} & \multirow{3}{*}{$\begin{array}{l}\text { SET7/9 down-regulation } \\
\text { is positively correlated } \\
\text { with poor prognosis }[120 \text {, } \\
124]\end{array}$} & $\begin{array}{l}\text { HDAC6 (interaction) } \\
\text { [120] }\end{array}$ & $\begin{array}{l}\text { Decreased } \\
\text { de-acetylation activity } \\
\text { of HDAC6 }\end{array}$ & $\begin{array}{l}\text { Increased cell proliferation and wound } \\
\text { healing rate [120] }\end{array}$ \\
\hline & & & & RIOK1 (K411) [124] & $\begin{array}{l}\text { Ubiquitination of } \\
\text { RIOK1 }\end{array}$ & $\begin{array}{l}\text { Increased cell proliferation, migration, and } \\
\text { invasion }[124] \\
\text { Enhanced CRC metastasis in vivo }\end{array}$ \\
\hline & & & & $\begin{array}{l}\text { SIRT1 (K233, K235, } \\
\text { K236, K238) [50] }\end{array}$ & $\begin{array}{l}\text { Disrupted binding of } \\
\text { SIRT1 to p53 }\end{array}$ & Induced p53 deacetylation [50] \\
\hline \multirow[t]{2}{*}{$\begin{array}{l}\text { Human liver } \\
\text { cancer }\end{array}$} & \multirow[t]{2}{*}{ Oncogene } & \multirow[t]{2}{*}{$\begin{array}{l}\text { Overexpression } \\
{[43,144]}\end{array}$} & \multirow[t]{2}{*}{$\begin{array}{l}\text { SET7/9 up-regulation is } \\
\text { positively correlated with } \\
\text { tumor metastasis, } \\
\text { recurrence, large tumor } \\
\text { size, and poor tumor } \\
\text { differentiation }[43,144]\end{array}$} & E2F1 (K185) [43] & Stabilization of E2F1 & $\begin{array}{l}\text { Decreased cell proliferation, migration and } \\
\text { invasion; } \\
\text { Decreased expression of E2F1 downstream } \\
\text { targets cyclin A2, cyclin E1 and CDK2 [43] }\end{array}$ \\
\hline & & & & $\begin{array}{l}\text { ZBTB20 (interaction), } \\
\text { CDKN2D (interaction) } \\
{[144]}\end{array}$ & & $\begin{array}{l}\text { Increased ZBTB20 and CDKN2D } \\
\text { expression; } \\
\text { Decreased cell proliferation [144] }\end{array}$ \\
\hline \multirow[t]{3}{*}{$\begin{array}{l}\text { Human lung } \\
\text { cancer }\end{array}$} & \multirow[t]{3}{*}{ Oncogene } & \multirow[t]{3}{*}{-} & \multirow[t]{3}{*}{-} & E2F1(K185) $[19,39,41]$ & Degradation of E2F1 & $\begin{array}{l}\text { Enhanced TP73 expression; } \\
\text { Increased cell death; } \\
\text { Inhibited cell growth }[19,39,41]\end{array}$ \\
\hline & & & & Gli3 (K436, K595) [71] & $\begin{array}{l}\text { Stabilization of Gli3; } \\
\text { Increased Gli3-DNA } \\
\text { binding capacity. }\end{array}$ & $\begin{array}{l}\text { Suppression of Shh signaling; } \\
\text { Inhibited tumor growth and metastasis [71] }\end{array}$ \\
\hline & & & & $\begin{array}{l}\text { Mdm2 (interaction) } \\
{[44]}\end{array}$ & $\begin{array}{l}\text { Increased Mdm2 } \\
\text { expression }\end{array}$ & $\begin{array}{l}\text { Defects in DNA repair; } \\
\text { Enhanced cell apoptosis; } \\
\text { Increased sensitivity to genotoxic stress } \\
\text { [44] }\end{array}$ \\
\hline $\begin{array}{l}\text { Mice } \\
\text { intestinal } \\
\text { tumor }\end{array}$ & Oncogene & - & $\begin{array}{l}\text { SET7/9 up-regulation is } \\
\text { positively correlated with } \\
\text { tumor susceptibility [90] }\end{array}$ & YAP (interaction) [90] & $\begin{array}{l}\text { Nuclear accumulation } \\
\text { of } \beta \text {-catenin }\end{array}$ & $\begin{array}{l}\text { Decreased expression of Wnt-dependent } \\
\text { genes Lgr5, Axin2, and Myc; } \\
\text { Diminished Wnt-signaling activation; } \\
\text { Fewer intestinal tumors [90] }\end{array}$ \\
\hline $\begin{array}{l}\text { Human } \\
\text { gastric cancer }\end{array}$ & $\begin{array}{l}\text { Tumor } \\
\text { suppressor }\end{array}$ & $\begin{array}{l}\text { Down-regulation } \\
\text { [142] }\end{array}$ & $\begin{array}{l}\text { SET7/9 down-regulation } \\
\text { is positively correlated } \\
\text { with overall survival } \\
\text { [142] }\end{array}$ & $\begin{array}{l}\text { H3K } 4 \text { in promoter } \\
\text { regions of } S R E K 1 I P 1, \\
P G C \text { and } C C D C 28 B \\
{[142]}\end{array}$ & Enhanced transcription & $\begin{array}{l}\text { Increased cell proliferation, migration and } \\
\text { invasion; } \\
\text { Increased MMPs expression [142] }\end{array}$ \\
\hline $\begin{array}{l}\text { Human } \\
\text { glioma }\end{array}$ & $\begin{array}{l}\text { Tumor } \\
\text { suppressor }\end{array}$ & $\begin{array}{l}\text { Down-regulation } \\
{[140]}\end{array}$ & - & $\begin{array}{l}\text { H3K4 in the promoter } \\
\text { regions of DRAIC [140] }\end{array}$ & Enhanced transcription & $\begin{array}{l}\text { Increased cell proliferation, migration and } \\
\text { invasion [140] }\end{array}$ \\
\hline \multirow[t]{3}{*}{$\begin{array}{l}\text { Human } \\
\text { osteosarcoma } \\
\text { tumor }\end{array}$} & \multirow[t]{3}{*}{$\begin{array}{l}\text { Tumor } \\
\text { suppressor }\end{array}$} & \multirow[t]{3}{*}{-} & \multirow[t]{3}{*}{-} & $\mathrm{pRb}(\mathrm{K} 873)[96]$ & $\begin{array}{l}\text { Facilitation of } \\
\text { pRb-dependent } \\
\text { transcriptional } \\
\text { repression [96] }\end{array}$ & $\begin{array}{l}\text { Increased expression of E2F target genes } \\
E 2 F 1, C d c 6, D H F R, C d c 25 A \text {, and } C d c 2 \\
\text { downstream of pRb; } \\
\text { Reduced cell cycle arrest; } \\
\text { Induction of senescent cells [96] }\end{array}$ \\
\hline & & & & $\mathrm{pRb}(\mathrm{K} 810)[97,98]$ & $\begin{array}{l}\text { Hypo-phosphorylation } \\
\text { of } \mathrm{pRb}\end{array}$ & $\begin{array}{l}\text { Increased DHFR, } C d c 2 / 6, E 2 F 1 \text { expression; } \\
\text { Accelerated cell growth }[97,98]\end{array}$ \\
\hline & & & & p53 (K372) [18] & Stabilization of p53 & $\begin{array}{l}\text { Inhibited p53 activity; } \\
\text { Down-regulation of p21/WAF/CIP and } \\
\text { Bax downstream of p53; } \\
\text { Defect in cell cycle arrest [18] }\end{array}$ \\
\hline \multirow[t]{3}{*}{$\begin{array}{l}\text { Human } \\
\text { cervical } \\
\text { cancer }\end{array}$} & \multirow[t]{3}{*}{$\begin{array}{l}\text { Tumor } \\
\text { Suppressor }\end{array}$} & \multirow[t]{3}{*}{-} & \multirow[t]{3}{*}{-} & $\beta$-catenin (K180) [89] & $\begin{array}{l}\text { Degradation of } \\
\beta \text {-catenin }\end{array}$ & $\begin{array}{l}\text { Up-regulation of } \beta \text {-catenin and its } \\
\text { downstream targets } c \text {-myc and cyclin D1; } \\
\text { Increased cell proliferation [89] }\end{array}$ \\
\hline & & & & HIF-1a (K32) [93] & Degradation of HIF-1a & Increased cell motility [93] \\
\hline & & & & $\begin{array}{l}\text { DNMT1 } \\
(\text { K142, K1096) }[115,116]\end{array}$ & $\begin{array}{l}\text { Degradation of } \\
\text { DNMT1 }\end{array}$ & Reduced cell cycle arrest $[115,116]$ \\
\hline
\end{tabular}

*Letters and numbers in the brackets indicated the methylation site of SET7/9. K, lysine; H3K4, histone H3 lysine 4; interaction, direct interaction detected between SET7/9 and the protein, but no methylation event was reported. 
On the contrary, an opposite role of SET7/9 was reported in lung cancer, liver cancer, and intestinal tumor. In liver cancer, SET7/9 expression was significantly higher in clinical tumor sample than in normal tissues [43,144]. High SET7/9 expression is positively correlated with tumor metastasis, tumor size, and tumor recurrence $[43,144]$. In consistent with this, silencing of SET7/9 in liver cancer cells resulted in decreased cell proliferation, migration, and invasion [43,144] (Table 1). In lung cancer cells H1299 and A549, many targets of SET7/9 have been identified, including E2F1, Gli3, and Mdm2. Although SET7/9-mediated methylation may either promote or inhibit the degradation of its protein substrates, knockdown of SET7/9 all successfully suppressed the malignant phenotype of lung cancer cells, as revealed by several different studies $[19,39,41,44,71]$ (Table 1 ). Using an SET7/9-knockdown mice model, a study also showed that SET7/9 controls mice intestinal regeneration and tumorigenesis by regulating Wnt/ $\beta$-catenin and hippo/YAP signaling [90]. It was also found that up-regulation of SET7/9 is associated with increased susceptibility to tumorigenesis [90] (Table). However, similar to the cases of osteosarcoma tumor and cervical cancer, there's a lack of clinical evidences which may further confirm the oncogenic role of SET7/9 in lung cancer and intestinal tumor.

Compared with the cancer types mentioned above, the roles of SET7/9 in breast cancer and colorectal cancer are still controversial. SET7/9 can regulate the cellular biological behavior of breast cancer cells by direct methylation of Estrogen Receptor a or H3K4 methylation in the promoters of VEGF and RUNX2 [12,131,143] (Table 1). Loss of SET7/9 led to decreased cell proliferative and migratory abilities in vitro and inhibited tumor growth and angiogenesis in vivo [12,131,143] (Table 1). Clinically, SET7/9 was found to be an independent poor prognostic factor in breast cancer [131]. However, another study detected significantly lower SET7/9 expression in clinical samples of breast cancer and showed that SET7/9 contributes to the epigenetic regulation of epithelial-mesenchymal transition. Knockdown of SET7/9 evoked EMT transition, while overexpression of SET7/9 led to mesenchymalepithelial transition with upregulated E-cadherin and down-regulated vimentin [40].

For colorectal cancer (CRC), several studies have demonstrated a tumor-suppressing effect of SET7/9 through methylation of RIOK1 and SIRT1 or through direct interaction with HDAC6 [50,120,124]. Regardless of the different targets identified in these studies, knockdown of SET7/9 all caused increased cell proliferation, migration, and invasion in vitro and enhanced tumor metastasis in vivo $[50,120,124]$.
Furthermore, down-regulated SET7/9 expression was detected in clinical tumor samples of CRC, which also indicated worse prognosis [120] (Table 1). However, another study conducted proteomic profiling using serum samples from CRC patients and showed that SET7/9 expression increased from healthy controls to those with colorectal polyps and finally CRC patients. SET7/9 expression was significantly correlated with tumor stage and microsatellite instability, suggesting that SET7/9 may serve as a potential prognostic biomarker for CRC. This study, together with the results from Xie et al. (2011), has supported a tumor-promoting role of SET7/9 in CRC [42,145] (Table 1). The contradictory roles of SET7/9 in breast cancer and colorectal cancer reported by different studies may be due to a limited number of clinical cases or the different genetic background of enrolled patients. Future studies combining large scale clinical analyses, molecular analyses and in-vitro and in-vivo functional analyses are necessary to validate the function of SET7/9 in these cancer types.

\section{Potential inhibitors of SET7/9 for pharmacological intervention}

Given the critical role of SET7/9 in controlling protein expression, transcription activity, genome stability, cell cycle progression, cell growth and differentiation, SET7/ 9 has been implicated as a target for cancer therapy. So far, several histone methyltransferase inhibitors have been reported, including DZNep that targets PRC2 [146,147] and chaetocin and BIX-01294 that selectively target SUV39 and G9a [148,149].

An X-ray crystal structures of SET7/9 in complex with its potential inhibitor (R)-(3-(3-cyanophenyl)-1oxo-1-(pyrrolidin-1-yl)propan-2-yl)-1,2,3,4-tetrahydro isoquino-line-6-sulfonamide have been deposited into the Protein Data Bank (Protein database entry 4e47). Two amine analogues of coenzyme S-(5'-adenosyl)-1methionine (AdoMet), DAAM-3 (DiAzaAdoMet-3) and AAM-1 (AzaAdoMet-1) that bind to the substrate-binding site of SET7/9 and inhibit SET7/9 activity were designed and synthesized [150,151]. More recently, another novel potent inhibitor of SET7/9, (R)-PFI-2 was discovered [83]. (R)-PFI-2 treatment in murine embryonic fibroblasts (MEFs) caused similar effects with SET7/9 deficiency in the subcellular localization and transcriptional activity of YAP via a substrate-competitive inhibitory mechanism [83]. MCF7 cells treated with (R)-PFI-2 demonstrated a dose-dependent increase of nuclear YAP and elevated expression of YAP target genes, AREG and CY61 [83]. Thus, (R)-PFI-2 may be used in the modulation of the Hippo pathway by inhibiting SET7/9. However, the effects of these SET7/9 
inhibitors on the biological feature of cancer cells haven't been examined.

Apart from all the SET7/9 inhibitors mentioned above, a clinically approved anti-drug, cyproheptadine was found to suppress estrogendependent MCF7 cell growth by inhibiting SET7/9 enzymatic activity and abolishing SET7/9-mediated stabilization of ERa [152]. The finding suggested a possibility to re-purpose cyproheptadine for breast cancer treatment [152]. With more in-vitro and in-vivo experimental evidences, the SET7/9 inhibitors identified so far may serve as chemical probe tool to interrogate the biological function of SET7/9, or more importantly, as potential chemical agents for pharmacological intervention in clinical treatment of cancer.

\section{Conclusion and prospect}

Methylation-associated modulation of cellular biological processes and signaling pathways have received increased attention in recent years $[153,154]$. As an important methyltransferase, the methylation substrates of SET7/9 vary from histones to non-histone transcription factors, transcriptional coactivators, hormone receptors, DNA cytosine methyltransferases, and other histone methyltransferases (Table 1). Recently, several studies have also demonstrated that SET7/ 9 can regulate the expression and activities of some proteins simply by proteinprotein interaction instead of direct methylation $[44,120]$. By interacting with various substrates and co-regulators, SET7/9 is involved in a complex molecular network underlying epigenetic modulation of gene transcription and regulation of cell cycle, cell motility, differentiation and proliferation, and cell apoptosis. However, due to its broad spectrum of protein targets, SET7/9 may act as either an oncogene or tumor suppressor in different cancer type with different genetic background and cellular contexts. Therefore, the biological and pathological effects of SET7/9 and its chemical inhibitors in each cancer type need to be clarified. Further clinical analysis using tumor samples and functional study using in vivo cancer models may provide a comprehensive view of the role of SET7/9 in cancer initiation and progression, which can help better evaluate the clinical value of SET7/9 as a potential risk predictor or therapy target.

\section{Acknowledgements}

The authors thank Dr. Martin Zulqarnain Muhammad for English editing and proof reading. This work was supported by the Saskatchewan Health Research Foundation of Canada, the National Natural Science Foundation of China (81071654), the
Southeast University Fundamental Research Funding Project (3224008704), Hangzhou Peak Discipline of Gastroenterology, the Key Laboratory of Integrated Traditional Chinese and Western Medicine for Biliary and Pancreatic Diseases of Zhejiang Province, the Key Laboratory of Clinical Cancer Pharmacology and Toxicology Research of Zhejiang Province (2020E10021), the Science and Technology Project of Hangzhou Health Commission (A20200113), the Zhejiang Medical and Health Science and Technology Plan (Grant No. WKJ-ZJ-2136 2019RC068 and 2021437779), and the Hangzhou Medical and Health Science and Technology Plan (Grant No. 2016ZD01, OO20190610 and A20200174). The funders had no role in study design, data collection and interpretation, or the decision to submit the work for publication.

\section{Competing Interests}

The authors have declared that no competing interest exists.

\section{References}

[1] Marmorstein R. Structure of SET domain proteins: a new twist on histone methylation. Trends Biochem Sci. 2003; 28(2): 59-62.

[2] Trievel RC, Beach BM, Dirk LM, et al. Structure and catalytic mechanism of a SET domain protein methyltransferase. Cell. 2002; 111: 91-103.

[3] Wilson J, Jing C, Walker P, et al. Crystal structure and functional analysis of the histone methyltransferase SET7/9. Cell. 2002; 111: 105-115.

[4] Manzur KL, Farooq A, Zeng L, et al. A dimeric viral SET domain methyltransferase specific to Lys27 of histone H3. Nat Struct Biol. 2003; 10: 187-196.

[5] Guo HB, \& Guo H. Mechanism of histone methylation catalyzed by protein lysine methyltransferase SET7/9 and origin of product specificity. PNAS. 2007; 104(21): 8797-8802.

[6] Tschiersch B, Hofmann A, Krauss V, et al. The protein encoded by the Drosophila position-effect variegation suppressor gene $\mathrm{Su}(\mathrm{var}) 3-9$ combines domains of antagonistic regulators of homeotic gene complexes. EMBO J. 1994; 13: 3822-3831.

[7] Jones RS and Gelbart WM. The Drosophila polycomb-group gene enhancer of zeste contains a region with sequence similarity to trithorax. Mol Cell Biol. 1993; 13: 6357-6366.

[8] Stassen MJ, Bailey D, Nelson S, et al. The Drosophila trithorax proteins contain a novel variant of the nuclear receptor type DNA binding domain and an ancient conserved motif found in other chromosomal proteins. Mech Dev. 1995; 52: 209-223.

[9] Chuikov S, Kurash JK, Wilson JR, et al. Regulation of p53 activity through lysine Methylation. Nature. 2004; 432: 353-360.

[10] Huang J, Sengupta R, Espejo AB, et al. p53 is regulated by the lysine demethylase LSD1. Nature. 2007; 449: 105-108.

[11] Shi X, Kachirskaia I, Yamaguchi H, West LE, Wen H, Wang EW, Dutta S, Appella E, Gozani O: Modulation of p53 function by SET8-mediated methylation at lysine 382. Mol Cell. 2007; 27: 636-646.

[12] Subramanian K, Jia D, Kapoor-Vazirani P, et al. Regulation of estrogen receptor alpha by the SET7 lysine methyltransferase. Mol Cell. 2008; 30: 336-347.

[13] Yang XD, Huang B, Li M, et al. Negative regulation of NF-KB action by Set9-mediated lysine methylation of the RelA subunit. EMBO J. 2009; 28(8): 1055-1066.

[14] Wang H, Cao R, Xia L, et al. Purification and functional characterization of a histone H3-lysine 4-specific methyltransferase. Mol Cell. 2001; 8: 1207-1217.

[15] Kwon T, Chang JH, Kwak E, et al. Mechanism of histone lysine methyl transfer revealed by the structure of SET7/9-AdoMet. The EMBO Journal. 2014; 22(2): 292-303.

[16] Qian C, Zhou MM. Set domain protein lysine methyltransferases: structure, specificity and catalysis. Cellular \& Molecular Life Sciences. 2006; 63(23): 2755-2763.

[17] Schapira M. Structural chemistry of human set domain protein methyltransferases. Current Chemical Genomics. 2001; 5(Suppl 1): 85-94.

[18] Ivanov GS, Ivanova T, Kurash J, et al. Methylation-acetylation interplay activates p53 in response to DNA damage. Mol Cell Biol. 2007; 27: 6756-6769.

[19] Lezina L, Aksenova V, Ivanova T, et al. KMTase Set7/9 is a critical regulator of E2F1 activity upon genotoxic stress. Cell Death Differ. 2014; 21(12): 1889-1899. 
[20] Ea CK, Baltimore D. Regulation of NF-kappaB activity through lysine monomethylation of p65. PNAS. 2009; 106: 18972-18977.

[21] Wang D, Zhou J, Liu X, et al. Methylation of SUV39H1 by SET7/9 results in heterochromatin relaxation and genome instability. PNAS. 2013; 110: 5516-5521.

[22] Liu Q, Geng H, Xue C, et al. Functional regulation of hypoxia inducible factor-1a by SET9 lysine methyltransferase. BBA-Mol Cell Res. 2015; 1853(5): 881-891.

[23] Oudhoff MJ, Freeman SA, Couzens AL, et al. Control of the hippo pathway by Set7-dependent methylation of Yap. Dev Cell. 2013; 26: 188-194.

[24] Dhayalan A, Kudithipudi S, Rathert P, et al. Specificity analysis-based identification of new methylation targets of the SET7/9 protein lysine methyltransferase. Chem Biol. 2011; 18: 111-120.

[25] Tewfik H, Kumar SA, Nicolas V, et al. Identification of rpl29 as a major substrate of the lysine methyltransferase set7/9. J BIOL CHEM. 2018; 293(33):12770-12780.

[26] Couture JF, Collazo E, Hauk G, et al. Structural basis for the methylation site specificity of SET7/9. Nat Struct Mol Biol. 2006; 13(2): 140

[27] Pradhan S, Chin HG, Estève PO, et al. SET7/9 mediated methylation of non-histone proteins in mammalian cells. Epigenetics. 2009; 4(6): 383-387.

[28] Keating ST, Ziemann M, Okabe J, et al. Deep sequencing reveals novel Set7 networks. Cell Mol Life Sci. 2014; 71(22): 4471-4486.

[29] Harris CC. p53: at the crossroads of molecular carcinogenesis and risk assessment. Science. 1993; 262: 1980-1981.

[30] Kastan MB, Onyekwere O, Sidransky D, et al. Participation of p53 protein in the cellular response to DNA damage. Cancer Res. 1991; 51: 6304-6311.

[31] Bunz F, Dutriaux A, Lengauer C, et al. Requirement for p53 and p21 to sustain G2 arrest after DNA damage. Science. 1998; 282: 1497-1501.

[32] Liu ZL, Wu XH, Lv JJ, et al. Resveratrol induces p53 in colorectal cancer through SET7/9. Oncol Lett. 2018; 17: 3783-3789.

[33] Lehnertz B, Rogalski JC, Schulze FM, et al. p53-dependent transcription and tumor suppression are not affected in Set7/9-deficient mice. Mol Cell. 2011; 43(4): 673-680.

[34] Campaner S, Spreafico F, Burgold $\mathrm{T}$, et al. The methyltransferase set7/9 (setd7) is dispensable for the p53-mediated dna damage response in vivo. Mol Cell, 2011; 43(4): 673-680.

[35] Feng L. Lin T. Uranishi H. et al. Functional analysis of the roles of posttranslational modifications at the p53 $\mathrm{C}$ terminus in regulating p53 stability and activity. Mol Cell Biol. 2005; 25: 5389-5395.

[36] Ren B, Cam H, Takahashi Y, et al. E2F integrates cell cycle progression with DNA repair, replication, and $\mathrm{G}(2) / \mathrm{M}$ checkpoints. Genes Dev. 2002; 16: 245-256.

[37] Irwin M, Marin MC, Phillips AC, et al. Role for the p53 homologue p73 in E2F-1-induced apoptosis. Nature. 2000; 407: 645-648.

[38] Koff A, Giordano A, Desai D, et al. Formation and activation of a cyclin E-cdk2 complex during the G1 phase of the human cell cycle. Science. 1992; 257: $1689-1694$

[39] Kontaki H, Talianidis I. Lysine methylation regulates E2F1-induced cell death. Mol cell. 2010; 39(1): 152-160.

[40] Montenegro MF, Sánchz-d-Campo, Ronzáz-urrro, et al. Tumor suppressor SET9 guides the epigenetic plasticity of breast cancer cells and serves as an early-stage biomarker for predicting metastasis. Oncogene. 2016; 35(47): 6143-6152.

[41] Gu Y, Wang Y, Wang X, et al. Opposite Effects of SET7/9 on Apoptosis of Human Acute Myeloid Leukemia Cells and Lung Cancer Cells. J Cancer. 2017; 8(11): 2069-2078

[42] Xie Q, Bai Y, Wu J, et al. Methylation-mediated regulation of E2F1 in DNA damage-induced cell death. J Recept Signal Transd. 2011;31(2): 139-146.

[43] Gu Y, Wang XL, Liu H, et al. SET7/9 promotes hepatocellular carcinoma progression through regulation of E2F1. Oncol Rep. 2018; 40: 1863-1874.

[44] Lezina L, Aksenova V, Fedorova O, et al. KMT Set7/9 affects genotoxic stress response via the $\mathrm{Mdm} 2$ axis. Oncotarget. 2015; 6(28): 25843-25855.

[45] Kitagawa M, Aonuma M, Lee SH. E2F-1 transcriptional activity is a critical determinant of $\mathrm{Mdm} 2$ antagonist-induced apoptosis in human tumor cell lines. Oncogene. 2008; 27: 5303-5314.

[46] Kubbutat M, Vousden KH. Keeping an old friend under control: regulation of p53 stability. Molecular Medicine Today. 1998; 4(6): 250-256.

[47] Konopleva M, Martinelli G, Daver N, et al. MDM2 inhibition: An important step forward in cancer therapy. Leukemia. 2020; 34(11): 2858-2874.

[48] Heyne K, Winter C, Gerten F, et al. A novel mechanism of crosstalk between the p53 and nfkb pathways: $\mathrm{mdm} 2$ binds and inhibits p65rela. Cell Cycle. 2013; 12(15): 2479-2492.

[49] Riley MF, Lozano G. The Many Faces of MDM2 Binding Partners. Genes \& cancer. 2012; 3:226-239.

[50] Liu X, Wang D, Zhao Y, Tu B, Zheng Z, Wang L, Wang H, Gu W, Roeder RG, Zhu WG: Methyltransferase Set7/9 regulates p53 activity by interacting with Sirtuin 1 (SIRT1). PNAS. 2011; 108(5): 1925-1930.

[51] Brunet A, Sweeney LB, Sturgill JF, et al. Stress-dependent regulation of FOXO transcription factors by the SIRT1 deacetylase. Science. 2004; 303(5666): 2011-2015.

[52] Motta MC, et al. (2004) Mammalian SIRT1 represses forkhead transcription factors. Cell 116:551-563.

[53] Bradbury CA, Khanim FL, R Hayden R, et al. Histone deacetylases in acute myeloid leukaemia show a distinctive pattern of expression that changes selectively in response to deacetylase inhibitors. Leukemia 2005; 19:1751-1759.
[54] Huffman DM, Grizzle WE, Bamman MM, et al. SIRT1 is significantly elevated in mouse and human prostate cancer. Cancer Res. 2007; 67: 6612-6618.

[55] Yi J, Luo J. SIRT1 and p53, effect on cancer, senescence and beyond. BBA-Proteins Proteom. 2010; 1804(8): 1684-1689.

[56] Perkins ND. The diverse and complex roles of nf-kb subunits in cancer. Nat Rev Cancer. 2012; 12(2): 121-132.

[57] Ghosh S, May MJ, Kopp EB. NF-kB and Rel proteins: evolutionarily conserved mediators of immune responses. Annual Rev Immun. 1998; 16(1): 225-260.

[58] $\mathrm{Hu} \mathrm{HY}$, Li KP, Wang XJ, et al. Set9, NF-KB, and microRNA-21 mediate berberineinduced apoptosis of human multiple myeloma cells. Acta Pharmacol Sin. 2013; 34: 157-166.

[59] WuY, Zou F, Lu Y, et al. SETD7 promotes TNF-a-induced proliferation and migration of airway smooth muscle cells in vitro through enhancing NF-kB/CD38 signaling. Int Immunopharmacol. 2019; 72: 459-466.

[60] Li M, Wang YX, Liu X, et al. Mir629 targets foxo3 to promote cell apoptosis in gastric cancer. Experimental and Therapeutic Medicine. 2020; 19(1): 294-300.

[61] Usami M, Kikuchi S, Takada K, et al. (2020). Foxo3a activation by hdac class iia inhibition induces cell cycle arrest in pancreatic cancer cells. Pancreas. 2020; 49(1):135-142.

[62] Zou Y, Tsai WB, Cheng CJ, et al. Forkhead box transcription factor FOXO3a suppresses estrogen-dependent breast cancer cell proliferation and tumorigenesis. Breast Cancer Res. 2008; 10: R21.

[63] Sun T, Zhang J, Deng B, et al. (2020). Foxo1 and foxo3a sensitize non-small-cell lung cancer cells to cisplatin-induced apoptosis independent of bim. Acta Biochim Biophys Sin (Shanghai). 2020; 52(12): 1348-1359.

[64] Xie Q, Hao Y, Tao Li, et al. Lysine methylation of FOXO3 regulates oxidative stress-induced neuronal cell death. EMBO Rep. 2012; 13(4):371-377.

[65] Calnan DR, Webb AE, White JL, et al. Methylation by set 9 modulates foxo3 stability and transcriptional activity. Aging. 2012; 4(7): 462-479.

[66] Kasper M, Regl G, Frischauf A M. GLI transcription factors: mediators of oncogenic Hedgehog signalling. Eur J Cancer. 2006; 2(4): 437-445.

[67] Dai P, Akimaru H, Tanaka $Y$, et al. Sonic hedgehog-induced activation of the Gli1 promoter is mediated by GLI3. J Biol Chem. 1999; 274: 8143-8152.

[68] Dai P, Shinagawa $T$, Nomura $T$, et al. Ski is involved in transcriptional regulation by the repressor and full-length forms of Gli3. Genes \& Development. 2002; 16: 2843-2848.

[69] Steg A, Amm HM, Novak Z, et al. Gli3 mediates cell survival and sensitivity to cyclopamine in pancreatic cancer. Cancer Biology \& Therapy. 2010; 10(9): 893-902.

[70] Iwasaki H, Nakano K, Shinkai K, et al. Hedgehog gli3 activator signal augments tumorigenicity of colorectal cancer via upregulation of adherencerelated genes. Cancer Science. 2013; 104(3): 328-336

[71] Fu L, Wu HL, Cheng SY. Set7 mediated Gli3 methylation plays a positive role in the activation of Sonic Hedgehog pathway in mammals. eLife. 2016; 5: e15690.

[72] Han NK, Sang CO, Kim JS, et al. Abrogation of gli3 expression suppresses the growth of colon cancer cells via activation of p53-sciencedirect. Exp Cell Res. 2012; 318(5): 539-549.

[73] Mellado B, Marin Aguilera M, Pereira MV. Molecular biology of castrationresistant prostate cancer: basis for the novel therapeutic targets. Arch Esp Urol. 2013; 66: 453-462.

[74] Conway K, Parrish E, Edmiston S, et al. Risk factors for breast cancer characterized by the estrogen receptor alpha A908G (K303R) mutation. Breast Cancer Res. 2007; 9: R36.

[75] Herynk MH, Parra I, Cui Y, et al. Association between the estrogen receptor alpha A908G mutation and outcomes in invasive breast cancer. Clin. Cancer Res. 2007; 13: 3235-3243.

[76] Ko S, Jungmi A, Song CS, et al. Lysine methylation and functional modulation of androgen receptor by Set9 methyltransferase. Mol Endocrinol. 2011; 25: 433-444.

[77] Zhou Q, Shaw PG, Davidson NE. Epigenetics meets estrogen receptor: regulation of estrogen receptor by direct lysine methylation. Endocr Relat Cancer. 2009; 16: 319-323.

[78] Katsogiannou M, Ziouziou H, Karaki S, et al. The hallmarks of castrationresistant prostate cancers. Cancer Treat Rev. 2015; 41:588-597.

[79] Zhao B, Ye X, Yu J, et al. TEAD mediates YAP-dependent gene induction and growth control. Genes Dev. 2008; 22: 1962-1971.

[80] Heallen T, Zhang M, Wang J, et al. Hippo pathway inhibits Wnt signaling to restrain cardiomyocyte proliferation and heart size. Science. 2011; 332: 458-761.

[81] Schlegelmilch K, Mohseni M, Kirak O, et al. Yap1 acts downstream of a-catenin to control epidermal proliferation. Cell. 2011; 144: 782-795.

[82] Kanai F, Marignani PA, Sarbassova D, et al. TAZ: a novel transcriptional co-activator regulated by interactions with 14-3-3 and PDZ domain proteins. EMBO J. 2000; 19: 6778-791.

[83] Barsyte-Lovejoy D, Li F, Oudhoff M J, et al. (R)-PFI-2 is a potent and selective inhibitor of SETD7 methyltransferase activity in cells[J]. Proceedings of the National Academy of Sciences, 2014, 111(35): 12853-12858.

[84] Cordenonsi M, Zanconato F, Azzolin L, et al. The Hippo transducer TAZ confers cancer stem cell-related traits on breast cancer cells. Cell. 2011; 147: 759-772.

[85] Pan D. The hippo signaling pathway in development and cancer. Dev. Cell 2010; 19: 491-505.

[86] Zhou D, Zhang $\mathrm{Y}, \mathrm{Wu} \mathrm{H}$, et al. Mst1 and Mst2 protein kinases restrain intestinal stem cell proliferation and colonic tumorigenesis by inhibition of 
Yes-associated protein (Yap) overabundance. Proc Natl Acad Sci USA. 2011; 108: E1312-E1320.

[87] Behrens J. The role of the Wnt signaling pathway in colorectal tumorigenesis. Biochem Soc Trans. 2005; 33: 672-675.

[88] Kikuchi A, Kishida S, Yamamoto H. Regulation of Wnt signaling by proteinprotein interaction and post-translational modifications. Exp Mol Med. 2006; 38: $1-10$

[89] Shen C, Wang D, Liu X. SET7/9 regulates cancer cell proliferation by influencing $\beta$-catenin stability. FASEB J. 2015; 29(10): 4313-4323.

[90] Oudhoff MJ, Braam MJ, Freeman SA. SETD7 controls intestinal regeneration and tumorigenesis by regulating Wnt/ $\beta$-catenin and hippo/YAP signaling. Dev cell. 2016; 37(1): 47-57.

[91] Ke X, Fei F, Chen Y, et al. Hypoxia upregulates cd147 through a combined effect of hif-1a and sp1 to promote glycolysis and tumor progression in epithelial solid tumors. Carcinogenesis. 2012; 33(8): 1598-1607.

[92] Wang GL, Jiang BH, Rue EA. Hypoxia-inducible factor 1 is a basic-helix-loophelix-PAS heterodimer regulated by cellular O2 tension. Proc. Natl Acad Sci USA. 1995; 92: 5510-5514.

[93] Kim Y, Nam HJ, Lee J. Methylation-dependent regulation of HIF-1a stability restricts retinal and tumour angiogenesis. Nat Commun. 2016; 7: 10347.

[94] Classon M, Harlow E. The retinoblastoma tumour suppressor $\mathrm{n}$ development and cancer. Nat Rev Cancer. 2002; 2: 910-917.

[95] Manning AL, Dyson NJ. Prb, a tumor suppressor with a stabilizing presence. Trends in Cell Biology. 2011; 21(8): 433-441.

[96] Munro S, Khaire N, Inche A. Lysine methylation regulates the $\mathrm{pRb}$ tumour suppressor protein. Oncogene. 2010; 29(16): 2357-2367.

[97] Carr SM, Munro S, Kessler B. Interplay between lysine methylation and Cdk phosphorylation in growth control by the retinoblastoma protein. EMBO J. 2011; 30(2): 317-327.

[98] Carr SM, Munro S, Zalmas LP. Lysine methylation-dependent binding of 53BP1 to the $\mathrm{pRb}$ tumor suppressor. PNAS. 2014; 111(31): 11341-11346.

[99] Unoki M, Daigo Y, Koinuma J, et al. UHRF1 is a novel diagnostic marker of lung cancer. Br J Cancer. 2010; 103:217-222.

[100] $\mathrm{Li} \mathrm{XL}, \mathrm{Xu} \mathrm{JH}, \mathrm{Nie} \mathrm{JH}$, et al. Exogenous expression of UHRF1 promotes proliferation and metastasis of breast cancer cells. Oncol Rep. 2012; 28:375-383.

[101]Zhou L, Zhao X, Han Y, et al. Regulation of UHRF1 by miR-146a/b modulates gastric cancer invasion and metastasis. FASEB J. 2013; 27:4929-4939.

[102]Jazirehi AR, Arle D, Wenn PB. UHRF1: a master regulator in prostate cancer. Epigenomics. 2012; 4:251-252.

[103]Babbio F, Pistore C, Curti L, et al. The SRA protein UHRF1 promotes epigenetic crosstalks and is involved in prostate cancer progression. Oncogene. 2012; 31:4878-4887.

[104] Kofunato Y, Kumamoto K, Saitou K, et al. UHRF1 expression is upregulated and associated with cellular proliferation in colorectal cancer. Oncol Rep. 2012; 28:1997-2002.

[105]Young HJ, Ji-Young K, Woo PJ, et al. Methylation of uhrf1 by set7 is essential for DNA double-strand break repair. Nuclc Acids Research. 2019; 47(1):184-196.

[106]Rice JC, Briggs SD, Ueberheide B. Histone methyltransferases direct different degrees of methylation to define distinct chromatin domains. Mol Cell. 2003; 12(6): 1591-1598.

[107]Rao VK, Pal A, Taneja R. A drive in SUVs: from development to disease. Epigenetics. 2017; 12: 177e86.

[108]Chiba T, Saito T, Yuki K, et al. Histone lysine methyltransferase SUV39H1 is a potent target for epigenetic therapy of hepatocellular carcinoma. Int J Canc. 2015; 136: 289e98.

[109]Lu C, Yang D, Klement JD, et al. SUV39H1 represses the expression of cytotoxic T-lymphocyte effector genes to promote colon tumor immune evasion. Canc Immunol Res. 2019; 7: 414e27.

[110]Yang Z, He L, Lin K, et al. The KMT1AGATA3-STAT3 circuit is a novel self-renewal signaling of human bladder cancer stem cells. Clin Canc Res. 2017; 23: 6673e85.

[111]Kim G, Kim JY, Lim SC, et al. SUV39H1/DNMT3A-dependent methylation of the RB1 promoter stimulates PIN1 expression and melanoma development. FASEB J. 2018; 32: 5647e60.

[112]Wang JF, Yin XM, He W, et al. Suv39h1 deficiency suppresses clear cell renal cell carcinoma growth by inducing ferroptosis. Acta Pharmaceutica Sinica B. 2021; 11(2): 406-419.

[113] Kar S, Deb M, Sengupta D. An insight into the various regulatory mechanisms modulating human DNA methyltransferase 1 stability and function. Epigenetics. 2012; 7(9):994-1007.

[114]Chen T, Hevi S, Gay F. Complete inactivation of DNMT1 leads to mitotic catastrophe in human cancer cells. Nat Genet. 2007; 39:391-396.

[115]Estève PO, Chin HG, Benner J. Regulation of DNMT1 stability through SET7mediated lysine methylation in mammalian cells. PNAS. 2009; 106(13): 5076-5081.

[116]Estève PO, Chang YQ, Samaranayake M. A methylation and phosphorylation switch between an adjacent lysine and serine determines human DNMT1 stability. Nat Struct Mol Biol. 2011; 18(1):42.

[117]Valenzuela-Fernández A, Cabrero JR, Serrador JM, et al. Hdac6: a key regulator of cytoskeleton, cell migration and cell-cell interactions. Trends in Cell Biology. 2008; 18(6): 291-297.

[118]Zhang XH, Yuan ZG, Zhang YT, et al. HDAC6 modulates cell motility by altering the acetylation level of cortactin. Mol Cell. 2007; 27: 197-213.
[119]Deakin NO and Turner CE. Paxillin inhibits HDAC6 to regulate microtubule acetylation, Golgi structure, and polarized migration. J Cell Biol. 2014; 206: 395-413.

[120]Zhang SL, Du X, Tan LN, et al. Set7 interacts with HDAC6 and suppresses the development of colon cancer through inactivation of hdac6. Am J Transl Res. 2020; 12(2): 602-611.

[121]LaRonde-LeBlanc N, Wlodawer A. A family portrait of the RIO kinases. J Biol Chem. 2005; 280: 37297-37300.

[122]Read RD, Fenton TR, Gomez GG, et al. A kinome-wide RNAi screen in Drosophila Glia reveals that the RIO kinases mediate cell proliferation and survival through TORC2-Akt signaling in glioblastoma. PLoS Genetics. 2013; 9: e1003253.

[123] Weinberg F, Reischmann N, Fauth L, et al. The atypical kinase riok1 promotes tumor growth and invasive behavior. EBioMedicine. 2017; 20: 79-97.

[124]Hong X, Huang H, Ding Z, et al. Targeting posttranslational modifications of RIOK1 inhibits the progression of colorectal and gastric cancers. ELife. 2018; 31(7): e29511.

[125] Kouskouti A, Scheer E, Staub A. Gene-specific modulation of TAF10 function by SET9-mediated methylation. Mol Cell. 2004; 14(2):175-182.

[126]Yang JB, Huang J, Dasgupta M. Reversible methylation of promoter-bound STAT3 by histone-modifying enzymes. PNAS. 2010; 107(50): 21499-21504.

[127]Masatsugu T, Yamamoto K. Multiple lysine methylation of PCAF by Set9 methyltransferase. Biochem Biophys Res Commun. 2009; 381: 22-26.

[128] Balasubramaniyan N, Ananthanarayanan M, Suchy FJ. Direct methylation of FXR by Set7/9, a lysine methyltransferase, regulates the expression of FXR target genes. Am J Physiol Gastrointest Liver Physiol. 2012; 302(9): G937-G947.

[129]Li Y, Reddy MA, Miao F. Role of the histone H3 lysine 4 methyltransferase, SET7/9 in the regulation of NF-kappa B-dependent inflammatory genesRelevance to diabetes and inflammation. J Biol Chem. 2008; 283(39): 26771-26781.

[130]Paneni F, Costantino S, Battista R. Adverse epigenetic signatures by histone methyltransferase Set7 contribute to vascular dysfunction in patients with type 2 diabetes mellitus. Circ Cardiovasc Genet. 2015; 8:150-158.

[131]Zhang $Y$, Liu J, Lin J. The transcription factor GATA1 and the histone methyltransferase SET7 interact to promote VEGF-mediated angiogenesis and tumor growth and predict clinical outcome of breast cancer. Oncotarget. 2016; 7(9): 9859-9875.

[132] Ono M. Molecular links between tumor angiogenesis and inflammation: inflammatory stimuli of macrophages and cancer cells as targets for therapeutic strategy. Cancer Sci. 2008; 99(8):1501-1506.

[133]Gasparini G, Toi M, Gion M. Prognostic significance of vascular endothelial growth factor protein in node-negative breast carcinoma. J Natl Cancer Inst. 1997; 89:139-147.

[134]Mercer TR, Mattick JS. Structure and function of long noncoding rnas in epigenetic regulation. NAT STRUCT MOL BIOL. 2013; 20(3): 300-307.

[135] Yan X, Hu Z, Feng Y, et al. Comprehensive Genomic Characterization of Long Non-coding RNAs across Human Cancers. Cancer Cell. 2015; 28(4): 529-540.

[136]Akrami, R. Jacobsen, A. Hoell, J et al. Comprehensive analysis of long non-coding RNAs in ovarian cancer reveals global patterns and targeted DNA amplification. PLoS ONE. 2013; 8: e80306.

[137]Calin GA, Liu CG, Ferracin M, et al. Ultraconserved regions encoding ncRNAs are altered in human leukemias and carcinomas. Cancer Cell. 2007; 12: 215-229.

[138]Du Z, Fei T, Verhaak RG, et al. Integrative genomic analyses reveal clinically relevant long noncoding RNAs in human cancer. Nat Struct Mol Biol. 2013; 20: 908-913.

[139]Li J, Han L, Roebuck P, et al. TANRIC: An interactive open platform to explore the function of IncRNAs in cancer. Cancer Res. 2015; 75: 1-10.

[140]Li C, Feng SY, Chen L. Set7/9 promotes h3k4me3 at lncrna draic promoter to modulate growth and metastasis of glioma. Eur Rev Med Pharmacol Sci. 2020; 24(23): 12241-12250.

[141]Barth TK, and Imhof A. Fast signals and slow marks: the dynamics of histone modifications. Trends Biochem Sci. 2010; 35: 618-626.

[142] Akiyama Y, Koda Y, Byeon S. Reduced expression of SET7/9, a histone monomethyltransferase, is associated with gastric cancer progression. Oncotarget. 2016; 7(4): 3966-3983.

[143]Si WZ, Zhou JS, Zhao Y. SET7/9 promotes multiple malignant processes in breast cancer development via RUNX2 activation and is negatively regulated by TRIM21. Cell Death Dis. 2020; 11: 151.

[144]Chen Y, Yang S, Hu J. Increased expression of SETD7 promotes cell proliferation by regulating cell cycle and indicates poor prognosis in hepatocellular carcinoma. PloS One. 2016; 11(5): e0154939.

[145]Duan B, Bai J, Qiu J, et al. Histone-lysine N-methyltransferase SETD7 is a potential serum biomarker for colorectal cancer patients. EBioMedicine. 2018; 37: 134-143.

[146]Glazer RI, Hartman KD, Knode MC, et al. 3-Deazaneplanocin: a new and potent inhibitor of S-adenosylhomocysteine hydrolase and its effects on human promyelocytic leukemia cell line HL-60. BIOCHEM BIOPH RES CO. 1986; 135(2): 688-694.

[147]Tan J, Yang X, Zhuang L, et al. Pharmacologic disruption of polycombrepressive complex 2-mediated gene repression selectively induces apoptosis in cancer cells. Genes Dev. 2007; 21(9): 1050-1063.

[148]Kubicek S, O'Sullivan RJ, August EM, et al. (2007). Reversal of H3K9me2 by a small-molecule inhibitor for the G9a histone methyltransferase. Mol cell. 2007; 25(3): 473-481. 
[149]Greiner D, Bonaldi T, Eskeland R, et al. Identification of a specific inhibitor of the histone methyltransferase SU (VAR) 3-9. Nat chem biol. 2005; 1(3): 143-145.

[150]Mori S, Iwase K, Iwanami N, et al. Development of novel bisubstrate. Bioorgan Med Chem, 2010; 18(23): 8158-8166.

[151]Niwa H, Handa N, Tomabechi Y,et al. Structures of histone methyltransferase set7/9 in complexes with adenosylmethionine derivatives. Acta Crystallogr D Biol Crystallogr. 2013; 69(Pt 4): 595-602.

[152]Takemoto $\mathrm{Y}$, Ito A, Niwa H, et al. Identification of cyproheptadine as an inhibitor of SET domain containing lysine methyltransferase 7/9 (SET7/9) that regulates estrogen-dependent transcription. J med chem. 2016; 59(8): 3650-3660.

[153]Lin J, Li XD. Peptide-based approaches to identify and characterize proteins that recognize histone post-translational modifications. Chin Chem Lett. 2018; 29(7): 1051-1057.

[154]Temimi AHKA, Guo H, Mecinović J. Lysine possesses the optimal chain length for histone lysine methyltransferase catalysis. Sci Rep. 2017; 7(1): 16148. 